Please do not remove this page

RMIT

UNIVERSITY

\title{
Coincident multi-point observations of the E- and F-region decametre-scale plasma waves at high latitudes
}

Carter, Brett; Makarevich, Roman; Devlin, John; McDonald, AJ

https://researchrepository.rmit.edu.au/esploro/outputs/9921858251101341/filesAndLinks?institution=61RMIT_INST\&index=null

Carter, B., Makarevich, R., Devlin, J., \& McDonald, A. (2012). Coincident multi-point observations of the Eand F-region decametre-scale plasma waves at high latitudes. Journal of Atmospheric and Solar -

Terrestrial Physics, 80, 323-335. https://doi.org/10.1016/j.jastp.2012.02.014

Document Version: Accepted Manuscript

Published Version: https://doi.org/10.1016/j.jastp.2012.02.014

Repository homepage: https://researchrepository.rmit.edu.au

(C) 2012 Elsevier Ltd.

Downloaded On 2023/04/26 22:47:08 +1000

Please do not remove this page 
Thank you for downloading this document from the RMIT Research Repository.

The RMIT Research Repository is an open access database showcasing the research outputs of RMIT University researchers.

RMIT Research Repository: http://researchbank.rmit.edu.au/

\section{Citation:}

Carter, B, Makarevich, R, Devlin, J and McDonald, A 2012, 'Coincident multi-point observations of the E- and F-region decametre-scale plasma waves at high latitudes', Journal of Atmospheric and Solar - Terrestrial Physics, vol. 80, pp. 323-335.

See this record in the RMIT Research Repository at:

https://researchbank.rmit.edu.au/view/rmit:20579

Version: Accepted Manuscript

Copyright Statement: (c) 2012 Elsevier Ltd.

Link to Published Version:

tttp://dx.doi.org/10.1016/j.jastp.2012.02.014 


\title{
Coincident multi-point observations of the E- and F-region decametre-scale plasma waves at high latitudes
}

\author{
B. A. Carter ${ }^{*, a, b}$, R. A. Makarevich ${ }^{\mathrm{c}}$, J. C. Devlin ${ }^{\mathrm{a}}$, A. J. McDonald ${ }^{\mathrm{a}}$ \\ ${ }^{a}$ School of Engineering and Mathematical Sciences, La Trobe University, Bundoora, \\ Victoria 3086, Australia \\ ${ }^{b}$ now at: SPACE Research Centre, RMIT University, Melbourne, Victoria 3001, \\ Australia \\ ${ }^{c}$ Geophysical Institute and Department of Physics, University of Alaska Fairbanks, \\ Fairbanks AK 99775-7320, USA
}

\begin{abstract}
Presented is an extensive analysis of the E-region backscatter observed at magnetic latitudes $75^{\circ}-80^{\circ} \mathrm{N}$ by the PolarDARN component of the $\mathrm{Su}-$ per Dual Auroral Radar Network (SuperDARN). The statistical occurrence characteristics of the short-range echoes reveal significant differences from those of the auroral and sub-auroral SuperDARN radars. In particular, most backscatter is detected in the midnight sector in the closest range gates where the geometric magnetic aspect angles are in excess of $10^{\circ}$ where no backscatter is normally expected. One explanation offered is that intense ionisation layers significantly refract the radar waves allowing a regular detection of the backscatter from the nearest range gates. A statistical analysis of the spectral echo types within the PolarDARN dataset showed strong similarities with the auroral SuperDARN radars, despite significant differences in the geometric aspect angle coverage. The low-velocity echoes dominated the datasets, while the high-velocity echoes were observed rather sporadically in the morning sector. The location of the PolarDARN radars relative to the more-equatorward SuperDARN radars facilitates the use of a new experimental setup that has coincident and simultaneous HF radar coverage of the $\mathrm{E}$ and $\mathrm{F}$ regions on the same magnetic field lines. Using this configuration, the SuperDARN plasma flow measurements are employed to investigate the
\end{abstract}

\footnotetext{
*Corresponding author

Email address: brett.carter@rmit.edu.au (B. A. Carter)
} 
E-region phase velocity dependence on the electric field strength and the flow angle at multiple locations. By employing elevation angle estimates, a marked decrease in the normalised phase velocity with decreasing altitude is observed, which provides direct support to the previously suggested collisional depression of the irregularity phase velocity. It is also shown that the normalised phase velocity is smaller for higher electric fields, which is interpreted as being due to a change in the contribution of the convective effects to the plasma wave growth at decametre scales.

Key words: Ionosphere, Plasma waves, Polar cap, E region

\section{Introduction}

The magnetic-field-aligned irregularities or waves in the electron density are a common feature of the Earth's ionosphere. E-region irregularities are routinely observed using $\mathrm{UHF}, \mathrm{VHF}$ and $\mathrm{HF}$ radar systems in the equatorial and auroral regions and as such have been extensively studied in recent decades. The auroral irregularities also known as the radar aurora have been found to occur at a multitude of scales/wavelengths from a few centimetres corresponding to UHF frequencies to decametre scales for HF radar observations. The overall goal of this research has been to gain a better understanding of the E-region irregularities in the context of the plasmaphysical and geophysical conditions that result in their generation.

There are two plasma instabilities that are thought to generate most of the irregularities observed in the E region: the Farley-Buneman instability (FBI) and the gradient-drift instability (GDI) (e.g. Fejer and Kelley, 1980). The FBI operates when a substantial electric field exists (i.e. $>20 \mathrm{mV} / \mathrm{m}$ ), which results in a strong differential plasma flow between the collisionallydominated ions and the fully-magnetised electrons. The GDI operates when a background plasma density gradient exists (Simon, 1963), with the largest irregularity growth rates achieved when the gradient is aligned in the direction of the background electric field and perpendicular to the magnetic field (e.g. Fejer et al., 1984).

The vast majority of the E-region plasma wave observations have been conducted in the equatorial and auroral regions using coherent backscatter radar systems, with the polar cap irregularities much less investigated. Much of the work in the polar cap has been done using oblique sounders (Olesen et al., 1975; Iverson et al., 1975; Tsunoda et al., 1976), with slant E condition 
or slant E echoes attributed to scattering processes from FBI-generated irregularities. The coherent scatter radars, on the other hand, were usually used on a campaign basis (e.g. Kustov et al., 1996, 1997). The reported backscatter properties were such that it was suggested that E-region irregularities were solely generated by the FBI (Hanuise, 1983). As discussed by Hanuise (1983), the orientation of the magnetic field in the polar cap is close to vertical, implying that in order for GDI waves to be generated the plasma density gradient must have a large component in the horizontal direction. Therefore, the strong vertical gradients that exist due to particle precipitation would not cause the observations of GDI waves in the polar cap region. Hence the radar backscatter should only be associated with the FBI in the polar region; i.e. it should only be observed during periods of strong electric field with the backscatter power peaking in the direction of the current (Hanuise, 1983). This idea has been largely supported by observations (e.g. Iverson et al., 1975; Tsunoda et al., 1976). However, it was later put forward by Kustov et al. (1994) that the electric field, or equivalently the plasma flow velocity, is not the only factor that controls the E-region irregularity production and detection in the polar cap. Kustov et al. (1994) demonstrated that other factors such as electrical conductance, refraction effects in the 'inclined' E layer and the field-aligned currents (FACs) also affect the detection of E-region irregularities in the polar cap.

At E-region altitudes, where the electrons are magnetised and the ions are collisionally bound to the neutrals, the differential plasma drift between the ions and electrons, $V_{d}$, is approximately equal to the electron drift velocity, $\vec{V}_{e 0}$ :

$$
\vec{V}_{d} \simeq \vec{V}_{e 0} \simeq \frac{\vec{E} \times \vec{B}}{|\vec{B}|^{2}},
$$

where $\vec{E}$ and $\vec{B}$ are the background electric and magnetic fields, respectively. From the linear fluid theory of the FBI and GDI, the E-region irregularity phase velocity is known to vary with the cosine of the plasma flow angle $\theta$. It is also a strongly decreasing function of the off-perpendicular aspect angle $\alpha$ maximising in the direction perpendicular to the local magnetic field direction, i.e. at $\alpha=0^{\circ}$ (e.g. Fejer and Kelley, 1980; Sahr and Fejer, 1996). The observations in the auroral region showed though that these relationships are far more complicated, with different spectral echo types exhibiting different dependencies (e.g. Villain et al., 1987, 1990; Uspensky et al., 2001; Milan and Lester, 2001; Makarevich, 2010). In particular, the so-called Type 
I echoes that are believed to be generated by the FBI have been found to move with velocities that were smaller than the plasma drift component being limited by the ion acoustic speed $C_{s}$ (e.g. Nielsen and Schlegel, 1983, 1985). The phase velocity of the Type II echoes associated with the GDI was sometimes much smaller than the cosine component of the background flow (Milan et al., 2003; Makarevitch et al., 2004; Makarevich, 2010). The possible reasons as to why the E-region phase velocity was smaller than the plasma drift component were proposed to be the aspect angle attenuation of the phase velocity (Kustov et al., 1997; Koustov et al., 2002; Makarevich et al., 2006b, 2007), neutral wind effects (Koustov et al., 2002), and enhanced collision frequencies in the lower E region (Makarevitch et al., 2004; Koustov et al., 2005). More recently, the ion drift contribution has been demonstrated to be important for large aspect and flow angle observations (Uspensky et al., 2003, 2004; Makarevich et al., 2006a,b, 2007). In the nonlocal generalisation of the FBI given by Drexler et al. (2002) it was demonstrated that the growth of decametre-scale waves is dominated by convective processes. The implication for $\mathrm{HF}$ radar observations is that for strong electric fields (e.g. $\sim 50$ $\mathrm{mV} / \mathrm{m}$ ), the growth rates for the decametre-scale waves are relatively high and their phase speeds as measured on the ground should be between $C_{s}$ and the $\vec{E} \times \vec{B}$ drift component. However, for weaker electric fields the growth rates are smaller, which results in the dominance of convective effects and to a ground-based observer the phase speeds would approach the $\vec{E} \times \vec{B}$ drift.

In the past it has been customary for the investigations into the E-region phase velocity dependence on the plasma flow velocity to employ plasma flow measurements obtained from the $\mathrm{F}$ region. This technique utilises the fact that the magnetic field lines that join these regions act as equipotential lines. The experimental configurations used to conduct these works has varied greatly. These included measurements from co-located scattering volumes of UHF incoherent and VHF coherent radars (Nielsen and Schlegel, 1983, 1985; Koustov et al., 2002; Uspensky et al., 2003, 2004; Makarevich et al., 2006a, 2007) and comparisons between the near- and far-range measurements within the field-of-view (FoV) of a single HF radar (Milan and Lester, 1998; Makarevitch et al., 2004; Makarevich, 2008, 2010). Coincident comparisons with the E-region HF velocities were problematic though since the instrumentation is normally positioned to maximise overlaps in the farrange F-region gates. A promising experimental setup has been employed in the study by Kustov et al. (1997) in which the E- and F-region irregularities were observed, respectively, by the stereoscopic VHF and HF radars, on the 
same magnetic field lines. The benefit of such an experimental setup involving HF radars for studies of the E-region plasma waves was also realised (Chisham et al., 2007), but it has not been until more recently that this sort of radar configuration could actually be used.

In this study, the datasets collected by the PolarDARN component of the Super Dual Auroral Radar Network (SuperDARN) HF radars (Greenwald et al., 1995; Chisham et al., 2007) were analysed. The high-latitude locations of these radars allow the detection of E-region backscatter from the largely-unexplored polar region on a routine basis. The time interval studied here covers the recent deep solar minimum providing a good opportunity to establish the quiet-time echo occurrence trends and the associated physical characteristics of the polar cap ionosphere. In addition, the overlap with the auroral SuperDARN radars enables the observations of both E- and F-region backscatter on the same magnetic lines, giving a unique perspective of the ionospheric flow conditions that give rise to the E-region irregularities. The specific objectives of this study are: (1) to determine the typical occurrence patterns for the E-region backscatter from the polar cap and to compare them with those observed by the auroral SuperDARN radars and (2) to examine the plasma flow strength and flow-angle dependencies of the E-region irregularity velocity using the multi-point F-region plasma convection measurements.

\section{Observations}

\subsection{Instrumentation}

PolarDARN consists of two poleward-facing HF radars located at Rankin Inlet $\left(62.8^{\circ} \mathrm{N}, 266.9^{\circ} \mathrm{E}\right.$, geographic) and Inuvik $\left(68.4^{\circ} \mathrm{N}, 226.5^{\circ} \mathrm{E}\right.$, geographic) (Koustov et al., 2009), hereinafter referred to as RKN and INV, respectively. As most radars composing the SuperDARN array, the PolarDARN radars sequentially scan through 16 azimuthal beam directions separated by $\sim 3.25^{\circ}$ in 1 or 2 mins, depending on the mode of operation. The range resolution of the SuperDARN radars under the common radar scan modes is $45 \mathrm{~km}$ between $180 \mathrm{~km}$ and $3500 \mathrm{~km}$ (with some of the newer radars reaching as far as $4680 \mathrm{~km}$ ) from the radar location and the radars operate at frequencies between 8-20 $\mathrm{MHz}$.

The dataset available for analysis in this study was collected by the PolarDARN HF radars, RKN and INV, over the periods 20070601-20090430 and 20080601-20090430, respectively. The standard criteria for the exclusion 
of ground/sea scatter (i.e. low velocity and spectral width) were employed to ensure that only ionospheric scatter was included in the analysis. The datasets were further cleaned by excluding measurements characterised by low power $(\mathrm{SNR}<3 \mathrm{~dB})$ and/or large spectral width $(\mathrm{W}>500 \mathrm{~m} / \mathrm{s})$.

In order to separate the E- and F-region backscatter detected by the PolarDARN radars, three separate data exclusions were put in place and directly compared. The datasets considered were as follows: (1) all data from range gates up to and including $720 \mathrm{~km}$ (i.e. the same range boundary as that used for most SuperDARN radars in the recent works by Makarevich (2010) and Carter and Makarevich (2010)), (2) all data from ranges up to and including $405 \mathrm{~km}$ and (3) the same as 1 , but with the additional requirement of only including measurements with virtual heights less than or equal to 200 $\mathrm{km}$. The determination of the virtual height $h^{\prime}$ is possible using the angle of arrival information obtained by the radars and employing the following relation

$$
h^{\prime}=\left(R_{E}^{2}+2 r R_{E} \sin \delta+r^{2}\right)^{1 / 2}-R_{E},
$$

where $R_{E}$ is the radius of the Earth, $r$ is the slant range and $\delta$ is the measured elevation angle (Chisham et al., 2008). The virtual height was also employed by Milan et al. (2001) to separate the E- and F-region backscatter in the Iceland East SuperDARN radar data. Their conclusion was that 150 $\mathrm{km}$ was the appropriate altitude to separate these backscatter regions using an altitude profile of the echo occurrence measured by the Iceland East SuperDARN radar. In this profile a minimum in echo occurrence was observed at approximately $150 \mathrm{~km}$ (see their Fig. 1). Our value of $200 \mathrm{~km}$ was also selected using this approach, not shown here.

\subsection{Statistical occurrence patterns}

To directly compare the three resulting datasets, Fig. 1 shows the diurnal variations of echo occurrence. The thick, thin and dashed histograms represent the diurnal variation of echo occurrence for periods of low, $0 \leq \mathrm{Kp}<3$, moderate, $3 \leq \mathrm{Kp}<5$ and high, $5 \leq \mathrm{Kp} \leq 9$, levels of geomagnetic activity, respectively for the RKN (left column) and INV (right column) datasets with the legend shown in the top-left panel. Panels (a) and (b) include all echoes detected at ranges $\leq 720 \mathrm{~km}$, panels (b) and (c) include echoes with ranges $\leq$ $405 \mathrm{~km}$ and panels (d) and (e) include the data with virtual heights (ranges) $\leq 200 \mathrm{~km}(720 \mathrm{~km})$. The echo numbers were normalised to the maximum value for each $\mathrm{Kp}$ level, displayed at the top-right. 


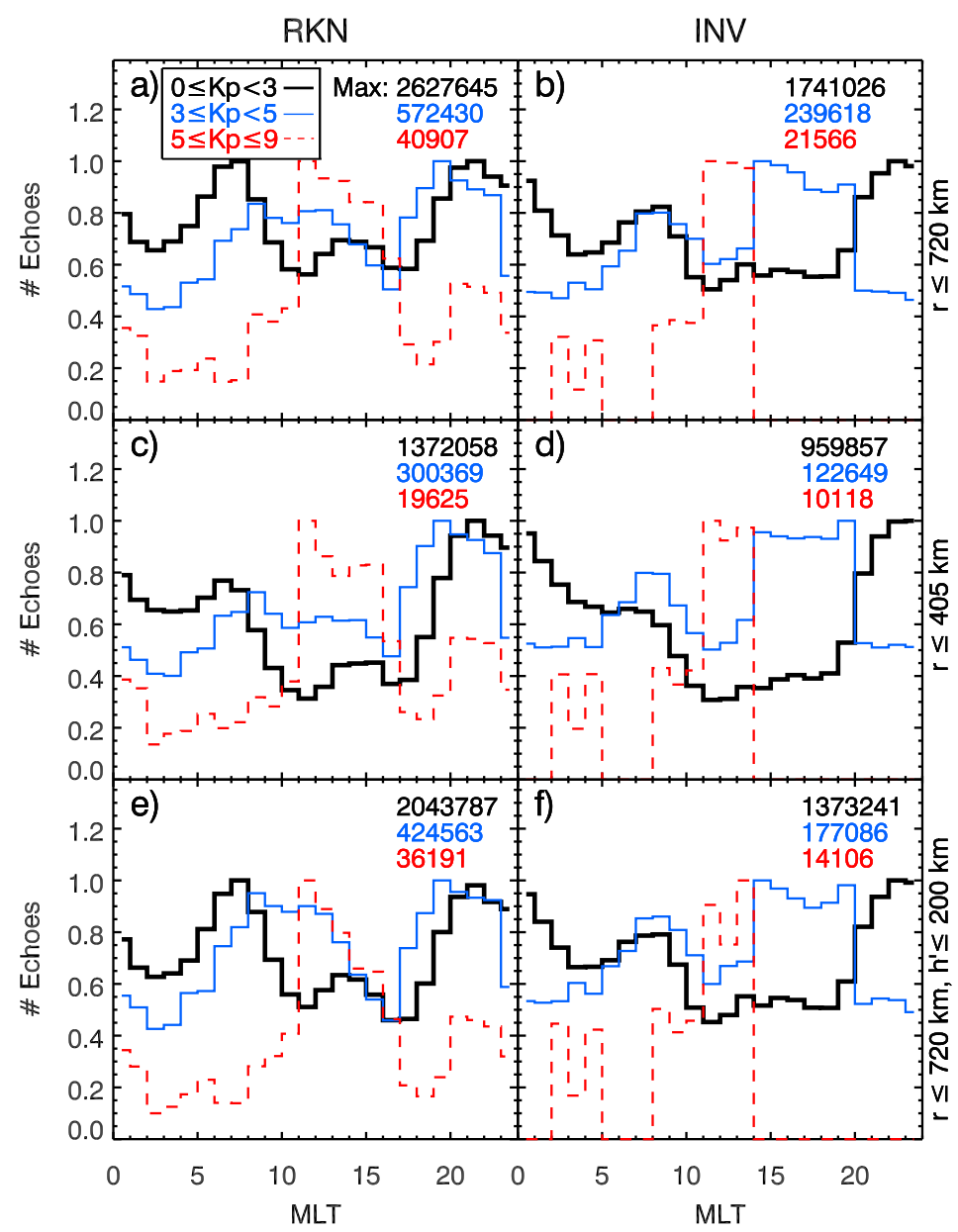

Figure 1: The diurnal variations of echo occurrence as measured by the RKN (left column) and INV (right column) radars during periods of low activity $(0 \leq \mathrm{Kp}<3$, thick), moderate activity $(3 \leq \mathrm{Kp}<5$, thin) and high activity $(5 \leq \mathrm{Kp} \leq 9$, dashed). The top, middle, and bottom panels represent the data that were collected at ranges $\leq 720 \mathrm{~km}, \leq 405 \mathrm{~km}$, and $\leq 720 \mathrm{~km}$ with virtual heights $\leq 200 \mathrm{~km}$, respectively. Each histogram is normalised to its maximum value displayed at the top-right of each plot. 
The diurnal trends for the RKN and INV radars displayed in Figs. 1a and b, respectively, show strong similarities. For example, for low activity the trends include two dominant echo occurrence peaks in the morning (0510 MLT) and midnight (20-01 MLT) sectors; a third, smaller peak in the afternoon sector (12-16 MLT) is also evident for the RKN dataset, but is not as pronounced in the INV dataset. For the higher levels of activity the echo detection rates are much smaller. This is most likely due to the low occurrence of the active periods themselves within the dataset, which mostly covers the period of the recent solar minimum. Similar characteristics are displayed by the datasets that were limited to ranges $\leq 405 \mathrm{~km}$, Figs. 1c and d, but with two significant differences. The first is the much lower value for the maximum within each plot; it is approximately half of the values shown in Figs. 1a and b. The second difference is the suppression of the morning and afternoon peaks, relative to the midnight peaks in both radars' datasets. However, the relative magnitudes of the maxima of the moderate activity level histograms to the low activity histograms are very similar; e.g. for RKN in panel (a) 572430/2627645 0.2 and in panel (c) $300369 / 1372058$ $\simeq 0.2$. Finally, the occurrence trends in Figs. 1e and $\mathrm{f}$ are very similar to those in panels (a) and (b), but with slightly lower values for the afternoon peaks and for the minima on either side of them. One more thing to note here is that the maximum values within each plot are substantially lower in panels (e) and (f) than those in panels (a) and (b), but not by as much as in panels (c) and (d).

To further investigate the effects that these exclusion criteria have on the PolarDARN datasets, the spatial occurrence patterns for the morning and midnight sectors are examined. Figure 2 shows the range-versus-beam echo occurrence plots for the RKN radar during 200806 (top row) and the INV radar during 200811 (bottom row) for (a)-(d) the morning and (e)-(f) midnight sectors. The monthly periods shown in Fig. 2 were manually chosen to represent other periods considered in this work. These chosen months are on both sides of a 4-month period considered next in Figs. 3 and 4. For each radar and each time sector, the spatial occurrence plots are shown for all data with ranges $\leq 720 \mathrm{~km}$ and for the further reduced dataset to virtual heights $\leq 200 \mathrm{~km}$. The total number of points included and the maximum occurrence value in each plot are shown in the top-left corner. The occurrence data in each plot are normalised to this maximum value. The colour scale is shown in panel (e).

Figure $2 \mathrm{a}$ shows a pronounced echo band centred at $\sim 540 \mathrm{~km}$ in range 

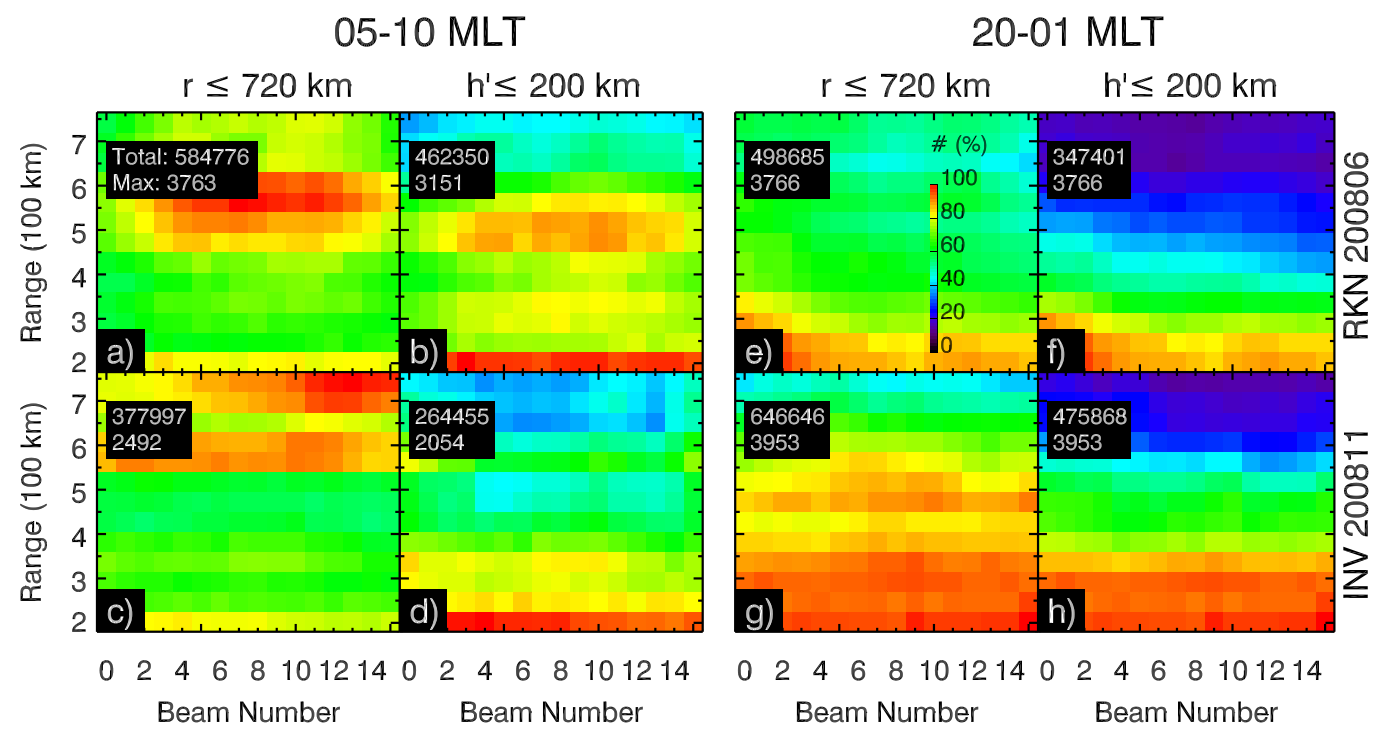

Figure 2: The spatial echo occurrence patterns for the RKN (top row) and INV (bottom row) radars in the (a)-(d) morning 05-10 MLT and (e)-(h) midnight 20-01 MLT sectors. Also presented are the echo occurrence patterns for the datasets that have been further limited to only contain echoes with virtual heights $\leq 200 \mathrm{~km}$. The total number of echoes and the maximum occurrence value are indicated at the top of each panel. The colour scale is given in panel (e) as the percentage of the maximum within each plot.

stretching across most beams, 2-14. An additional band is also shown in the first range gate $180 \mathrm{~km}$. In the reduced dataset, $h^{\prime} \leq 200 \mathrm{~km}$ in Fig. $2 \mathrm{~b}$, the farther echo band appears at shorter ranges, centred at $\sim 450 \mathrm{~km}$. The decrease with range within the farther band is now much more gradual. The maximum in the plot in the reduced dataset occurs in the first range gate rather than in the farther band (as was the case in Fig. 2a). This implies that a significant number of high-altitude (i.e. $h^{\prime}>200 \mathrm{~km}$ ) echoes were detected by RKN in the farther range gates. Similar features can be identified in the spatial occurrence patterns for the INV radar in Figs. 2c and d. For instance, the INV radar also detected a large number of echoes in the first range gate, as well as in the few further range gates, so that this first band appears to be wider for INV.

In the midnight sector, the patterns are quite different from those in the morning sector presented above. Figure $2 \mathrm{e}$ shows that most of the RKN echoes were detected from short ranges $r \leq 360 \mathrm{~km}$. The occurrence is also substantial at farther ranges across all beams, at $\sim 60 \%$, green cells. In the 
reduced dataset shown in Fig. 2f, the dominance of the short-range echo band is almost unchanged, however the number of echoes beyond the range of 495 $\mathrm{km}$ is greatly reduced to echo counts below $20 \%-30 \%$. It is also worth noting that the maximum occurrence value in the plot does not change between Figs. 2e and f. For the INV dataset shown in Fig. 2g, the majority of echoes were detected in the short range gates, $r \leq 360 \mathrm{~km}$. The echo occurrence at farther ranges is even higher than that for RKN, at values $>80 \%$. In the reduced INV dataset, Fig. 2h, the changes are very similar to those for the RKN dataset in Fig. $2 f$.

In the past, a simple range cut-off was used to exclude F-region echoes from the SuperDARN datasets (e.g. Makarevich, 2010, and references therein). It appears from the above analysis that this method does not work too well for the PolarDARN radars, at least in the morning sector where occurrence showed a second band of near-range echoes which could be of F-region origin, partly or entirely. Further restricting the datasets by only including echoes with virtual heights $\leq 200 \mathrm{~km}$ removes a substantial portion of these echoes so that occurrence patterns show a clear minimum at, and a decrease towards, the maximum range considered. This suggests that this additional restriction, which similar to that used by Milan et al. (2001), is more successful in removing F-region echoes. In the midnight sector, Fig. 2e-h shows no evidence of a significant contamination by F-region echoes. Based on the above, the datasets used for the remainder of this study have been reduced using the additional criterion of $h^{\prime} \leq 200 \mathrm{~km}$.

The spatial occurrence patterns in the morning and midnight sectors for a selected 4-month period are now analysed in monthly intervals. Figure 3 has a similar format to Fig. 2; it shows the range-versus-beam echo occurrence plots for the (a)-(d) RKN and (e)-(h) INV radars in the morning sector (05-10 MLT) in the monthly periods between 200807-200810. Once again for both radars, a large number of echoes were detected in the first range gate, where the cell of the maximum echo occurrence was located in 3 out of 4 months for RKN and 2 out of 4 months for INV. Both radar datasets show the existence of two echo bands: one between 450-630 km and the other one at ranges below $405 \mathrm{~km}$. The spatial patterns of both radars are very similar.

The spatial patterns for the midnight sector 20-01 MLT for the same months as above are presented in Fig. 4. The echo occurrence distributions were very similar for RKN and INV for each month plotted. The distinct features include the existence of just one echo band which was observed in the shortest ranges and the echo occurrence decreasing with range at a very 


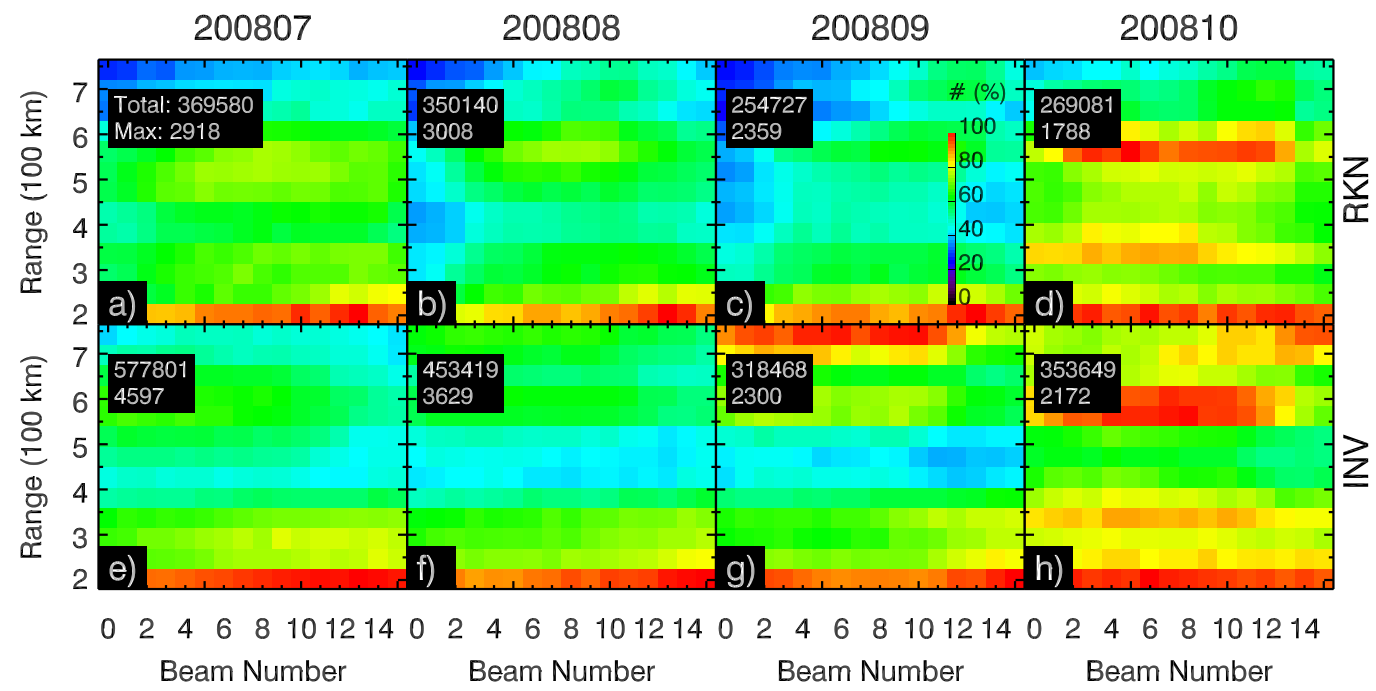

Figure 3: The same as Figs. 2b and d, but for the morning sector 05-10 MLT during months 200807-200810.

similar rate for all beams. A feature that was not clearly observed in the morning sector, Fig. 3, was an apparent shift in the range of the E-region echo band from month to month. In 200807-200810 the poleward boundary of the echo band appears to move farther from the radar, e.g. consider the range of the $45 \%$ echo occurrence values (i.e. light-blue cells) in beam 15 for RKN which gradually shifts from $\sim 370 \mathrm{~km}$ in 200807 to $\sim 585 \mathrm{~km}$ in 200809, Figs. 4a-c.

In can be concluded from analysis of the PolarDARN radar data thus far that both radars observe very similar echo occurrence patterns, as would be expected from their similar latitudinal positions and look-directions and hence their similar flow- and aspect-angle coverages. One similarity between the echo occurrence patterns observed by the PolarDARN radars is that the large number of echoes were detected in the first range gate in the morning sector alongside the second and weaker echo band at the farther ranges. The spatial echo occurrence patterns were somewhat different in the midnight sector compared to the morning sector in that only one strong echo band was observed in the short ranges (i.e. no second band).

The statistical spectral characteristics of the short-range PolarDARN echoes are investigated next. Figure 5 shows the 2-D occurrence plots of the spectral width versus the Doppler velocity for the (a)-(d) RKN and (e)- 


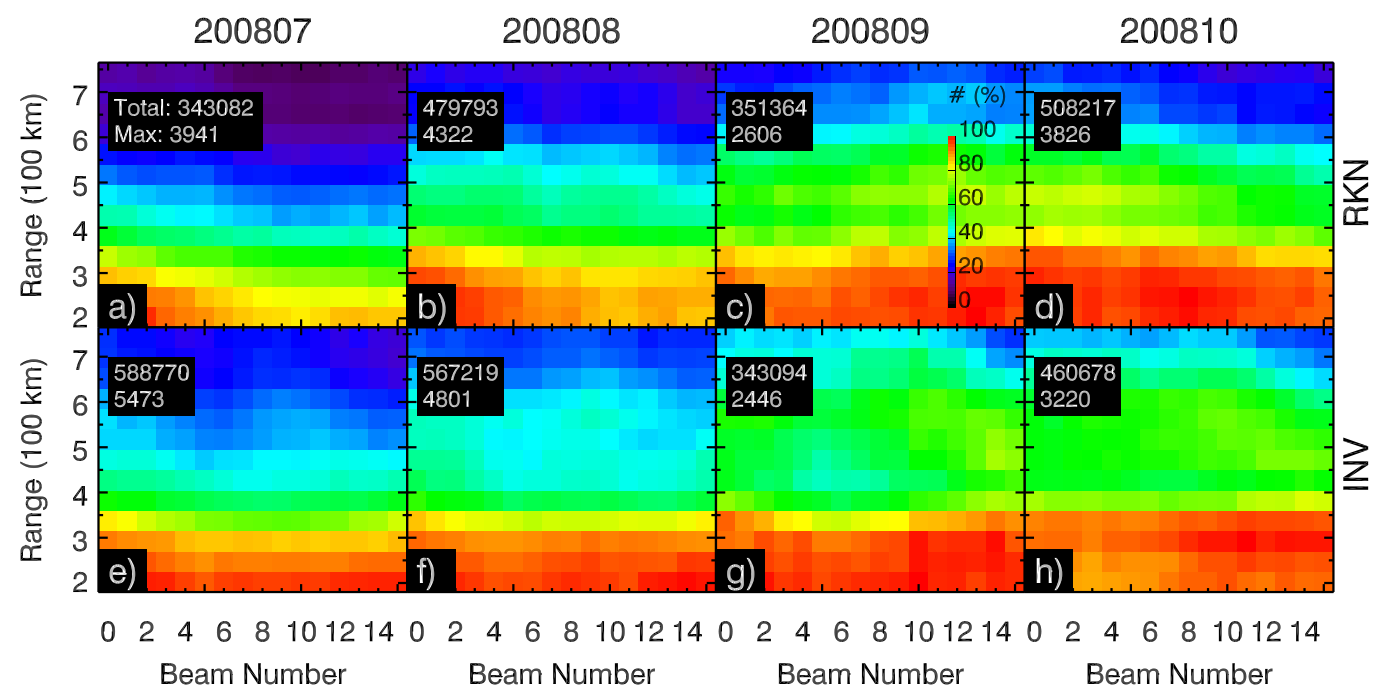

Figure 4: The same as Fig. 3, but for the midnight sector 20-01 MLT.

(h) INV radars in the morning sector in 200807-200810. The colour scale is shown in panel (c); the point occurrence data are scaled to the percentage of the maximum occurrence value within the plot. The bin size for the spectral width (Doppler velocity) was $20(25) \mathrm{m} / \mathrm{s}$.

There are two main echo populations present within the RKN dataset for all 4 months considered: one population centred at the Doppler velocity near zero and widths ranging $0-300 \mathrm{~m} / \mathrm{s}$ and another population centred at $\sim-390 \mathrm{~m} / \mathrm{s}$ with widths ranging $0-200 \mathrm{~m} / \mathrm{s}$. The lack of echoes close to the origin of these plots is simply due to the ground scatter exclusion of low width and low velocity, Sect. 2.1. The two echo populations are also present in the INV dataset, however the high-velocity population is not as pronounced as it is for RKN and is only clearly separated from the low-velocity population in 200807 and 200808.

It is interesting to note that the trend shown by the echo occurrence values of the high-velocity population from month to month in Fig. 5 is similar to that shown by the echo band at the farther ranges in the spatial distributions in Fig. 3. In particular, the maximum point occurrence values of the high-velocity population in the RKN dataset start at $\sim 25 \%$ in 200807 , which decreases to $\sim 10 \%$ in 200809 and then increases to $\sim 20 \%$ in 200810 . A very similar trend is observed in Figs. 3a-d for the second band at $\sim 540$ $\mathrm{km}$ which weakened between 200807-200809 before strengthening again in 


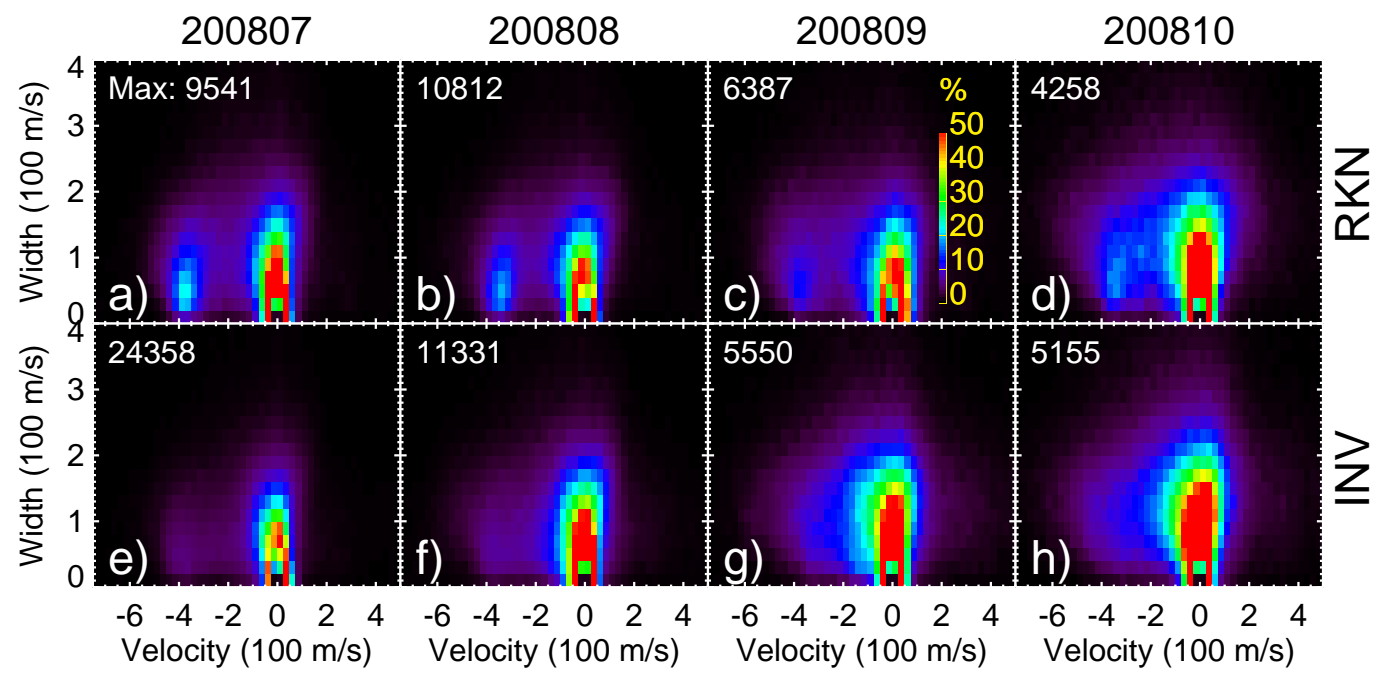

Figure 5: The 2-D point occurrence plots of the spectral width versus Doppler velocity for the (a)-(d) RNK and (e)-(h) INV radars. The data were collected in the morning sector 05-10 MLT in the months between 200807-200810. The maximum number of points within a plot cell in each panel is indicated at the top. The cells are coloured in the percentage of this value. The colour scale is shown in panel (c).

200810. This similarity may indicate that the high-velocity echo population is mostly detected within the second echo band rather than in the first range gate.

Figure 6 is the same as Fig. 5, but for the midnight sector. The two radar datasets show only one dominant echo population for all 4 months considered here. This population is analogous to the low-velocity population identified in the morning sector, with small Doppler velocities and spectral widths ranging $0-300 \mathrm{~m} / \mathrm{s}$. It can be concluded from Figs. 5 and 6 that two HF echo populations dominate the PolarDARN radar datasets: (1) highvelocity echoes with velocities close to $C_{s}$ and (2) low-velocity echoes with velocities near $\sim 0 \mathrm{~m} / \mathrm{s}$.

\subsection{Phase velocity and plasma convection}

A new method for studying the flow angle effects in the E-region backscatter characteristics for events where the plasma flow is not necessarily uniform is now introduced and employed in the last part of this study. As previously mentioned, the poleward location of the PolarDARN radars relative to the auroral SuperDARN radars provides an excellent opportunity to observe 


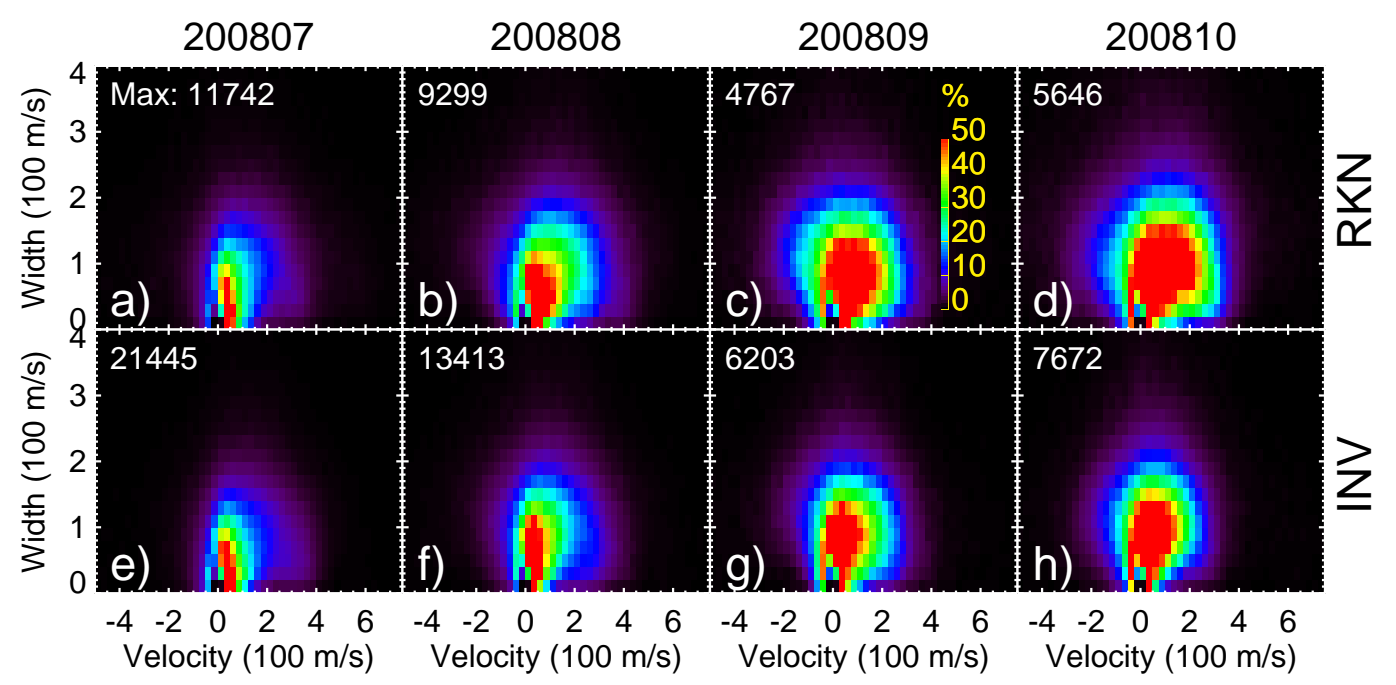

Figure 6: The same as Fig. 5, but for the midnight sector 20-01 MLT.

echoes from scattering volumes located in the $\mathrm{E}$ and $\mathrm{F}$ regions on the same field lines. An important innovation of this study is that these observations are conducted in multiple locations so that the flow and aspect angle dependencies can be studied in a wide range of flow and aspect angles, whereby improving opportunities to decouple one dependence from the other.

The method employed here uses the SuperDARN F-region plasma velocity vectors produced by the map potential technique (Ruohoniemi and Baker, 1998; Ruohoniemi and Greenwald, 2005; Pettigrew et al., 2010) which are projected to the E region. More specifically, the data from the entire SuperDARN array in the northern hemisphere, not just the closest radar is used. For all radars, only the data from ranges $\geq 765 \mathrm{~km}$ were included (i.e. E-region echoes were excluded). In addition, the IMF input to the potential technique was provided by the WIND spacecraft and the 8th order spherical harmonic fits were chosen to give higher spatial resolution. The fit vectors from the map potential technique were used to infer the plasma flow magnitude $V_{e 0}$ and direction at multiple locations above the RKN E-region FoV at 2-min resolution. For this analysis, a particular kind of fit vectors was employed, i.e. 'true' vectors obtained by merging the 'raw' fit vectors from the fitting procedure alone with the nearest line-of-sight (l-o-s) velocity measurements if these were available. Thus, by employing the 'true' vectors as opposed to the raw 'fit' vectors, a more data-based representation of the plasma flow is used (A. Grocott and M. Lester, private communication, 


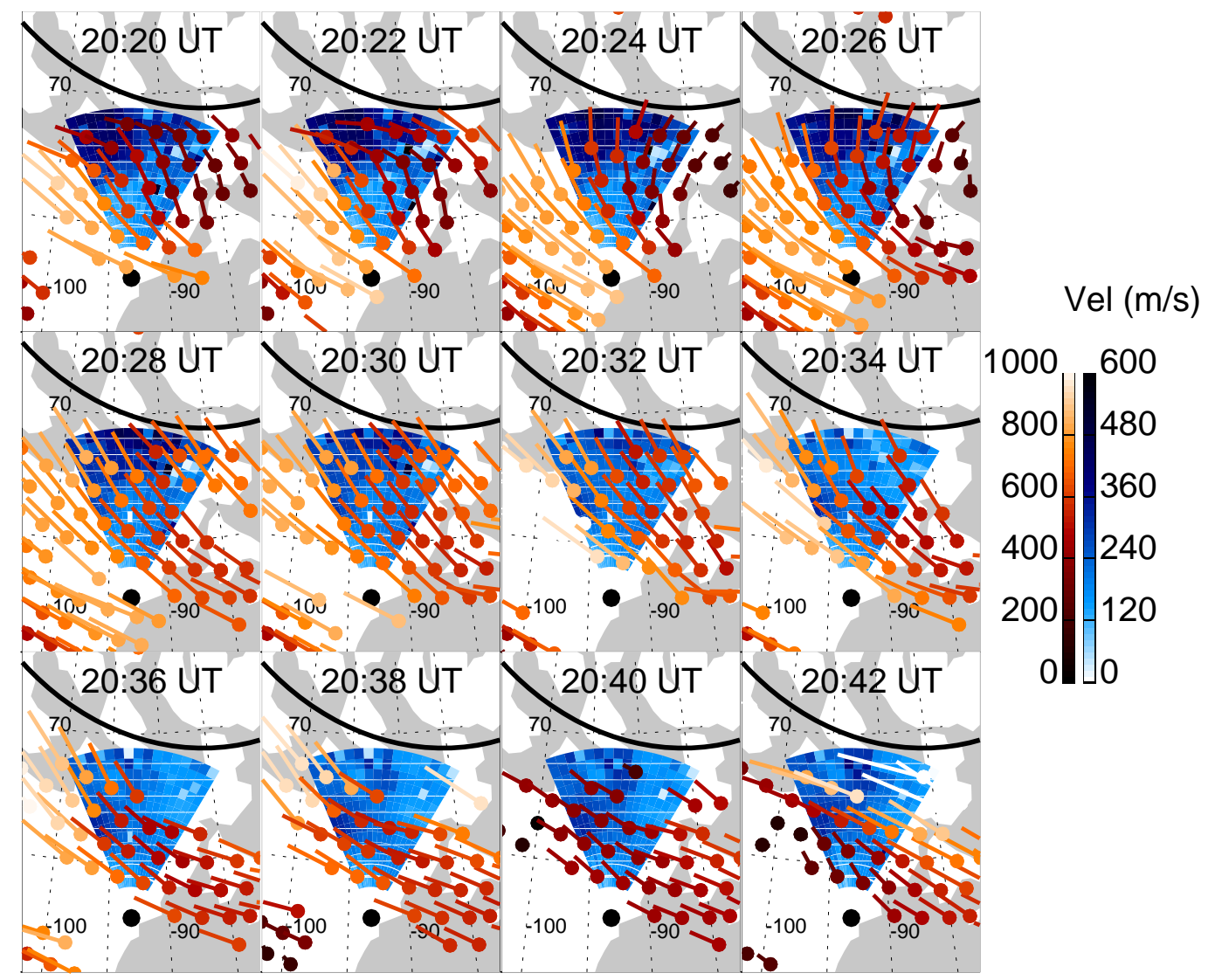

Figure 7: Geographic plots displaying the RKN radar l-o-s velocity data for each 2-min interval between 20:20-20:44 UT on 6 Aug 2007 with the SuperDARN plasma flow fit vectors overlaid. The velocity colour scales are shown on the right.

2010). The same analysis was repeated using the 'raw' fit vectors, with little effect on the results.

Figure 7 shows the geographic fan plots of the RKN l-o-s velocity data for every 2-min interval between 20:20-20:44 UT on 6 Aug 2007 with the calculated plasma flow fit vectors overlaid, after being projected down to the E region. The E-region l-o-s velocities (plasma flow vectors) are represented by the blue (orange) colour scales on the right of the figure. It can be seen that during this interval there were plenty of vectors generated by the SuperDARN map potential technique that were directly above the RKN near-range FoV. The vectors show that the plasma flow within the RKN E-region FoV was quite dynamic, with significant changes occurring from 
interval to interval. In addition, the wide range of vector directions for this event allows the examination of the echo characteristics over a large range of flow angles; this coverage is greater than that in the L-shell angle technique where the angle between the radar l-o-s and the direction of the magnetic $\mathrm{L}$ shell, $\phi$, is limited to within $\sim 50^{\circ}$ for a single radar (e.g. Makarevich, 2008). In addition, the plasma flow strength effects can be examined in more detail as plasma convection speeds also exhibited large variability even for a single time interval due to spatial variation. It is also worth noting that both high- and low-velocity echoes were observed by RKN throughout this event, indicated by the dark- and light-blue radar cells, respectively.

A re-examination of the E-region backscatter spectral characteristics, particularly the irregularity l-o-s velocity and its flow angle dependence, in the context of the plasma drift velocity $\vec{V}_{e 0}$ is now performed. For the event considered, the locations of the SuperDARN fit vectors were projected from their model height $200 \mathrm{~km}$ down to $110 \mathrm{~km}$ along the magnetic field lines given by the International Geomagnetic Reference Field (IGRF) model (Maus et al., 2005) and then the distances between these vectors and each RKN radar cell were calculated. The plasma drift speed $V_{e 0}$ and the flow angle $\theta$ for each RKN echo were estimated using the closest plasma flow vector, provided that this distance was less than $100 \mathrm{~km}$, otherwise the measurement was ignored. As the direction of the plasma flow vector was specified by its magnetic azimuth, the flow angle was defined as the difference between the magnetic azimuth of the radar l-o-s at each radar cell location and the magnetic azimuth of the flow vector. The result is that for plasma flows directed towards the west (east) of the radar l-o-s the calculated flow angle is positive (negative).

The spectral characteristics of the RKN short-range echoes are examined in Figs. 8a and b that show the spectral width versus the phase velocity scatter plots as observed by RKN between 20:20-20:50 UT, colour-coded in the virtual height $h^{\prime}$ and the plasma flow speed $V_{e 0}$, respectively. Figures $8 \mathrm{c}$ and $d$ show the virtual height versus the phase velocity for the same data as in Figs. 8a and b, but colour-coded in the spectral width and the plasma flow speed, respectively. Occurrence histograms are also shown in Fig. 8d for the phase velocity bins including all echoes (black) and for the altitude bins including the high-phase-velocity $(>350 \mathrm{~m} / \mathrm{s})$ and low-phase-velocity $(<350 \mathrm{~m} / \mathrm{s})$ echoes shown by the red and blue histograms, respectively. The scales for these histograms are given by the bars and the digits.

From the phase velocity histogram in Fig. 8d, it is clear that two spectral 


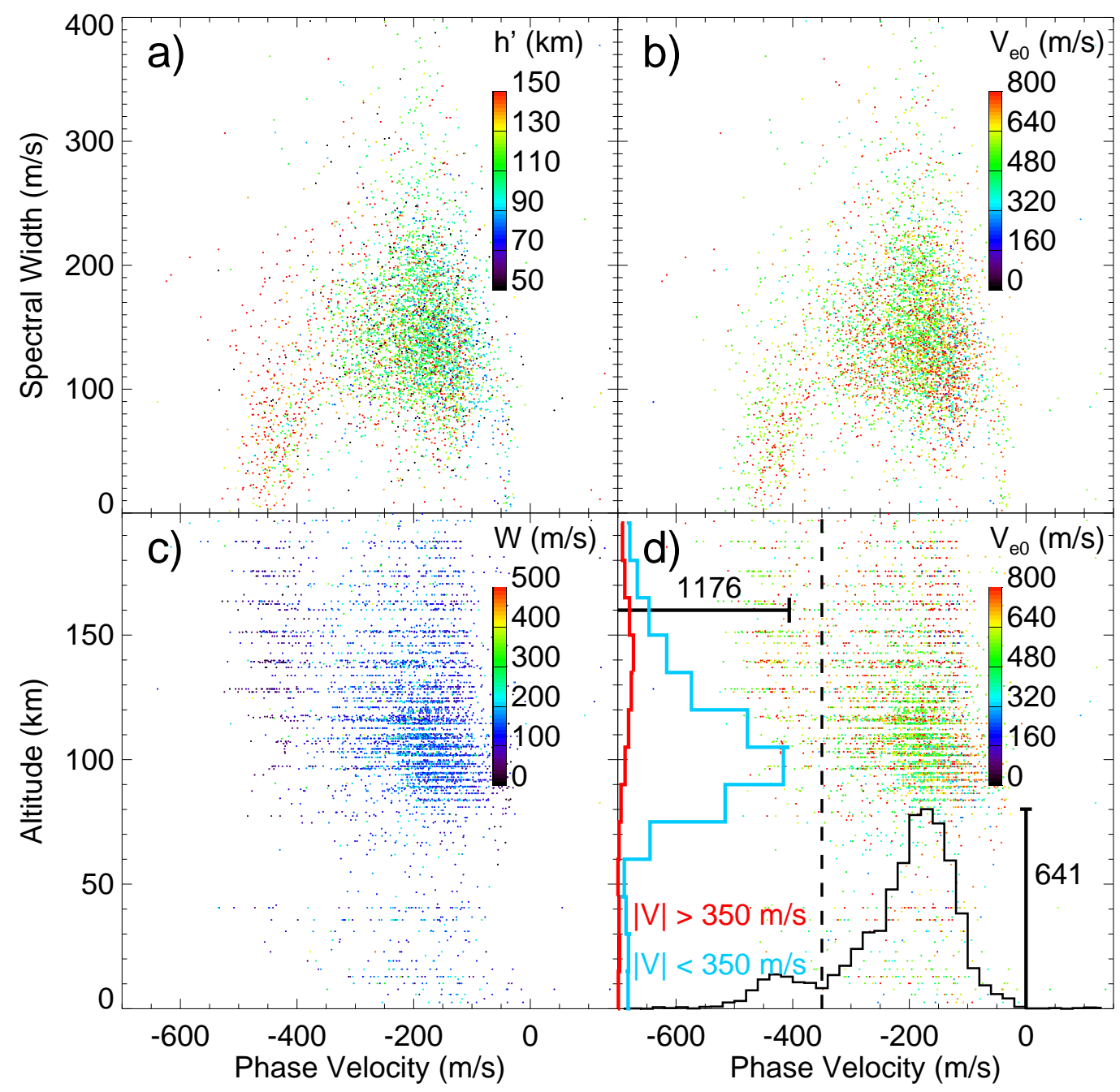

Figure 8: Scatter plots of (a) and (b) the spectral width versus the Doppler velocity and (c) and (d) the virtual height versus the Doppler velocity measured by RKN between 20:2020:50 UT on 6 Aug 2007. The data points are colour-coded in (a) the virtual height, (b) and (d) the plasma flow strength and (c) the spectral width. Altitude occurrence histograms are included in panel $(\mathrm{d})$ for points with high $(>350 \mathrm{~m} / \mathrm{s}$, red) and low velocities $(<350$ $\mathrm{m} / \mathrm{s}$, blue). The black histogram in panel (d) shows velocity distribution. The scales of these histograms are given by the bars and the digits. 


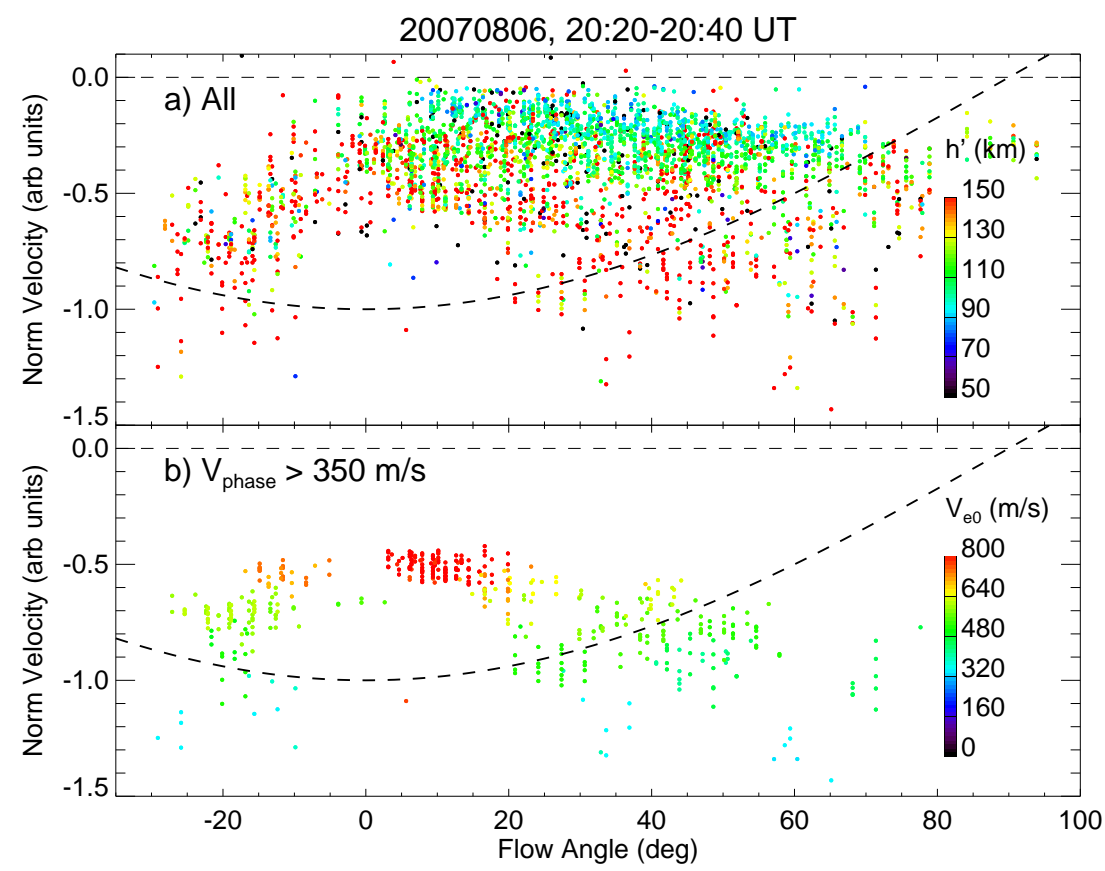

Figure 9: Scatter plots of normalised velocity versus flow angle (a) for all the data between 20:20-20:40 UT and (b) for the points with phase velocities exceeding $350 \mathrm{~m} / \mathrm{s}$.

echo populations were present during the interval studied. These echo populations include one with low phase velocities (centred at $V \simeq-175 \mathrm{~m} / \mathrm{s}$ ) and a large range of spectral widths $(50-250 \mathrm{~m} / \mathrm{s})$ and another with high phase velocities (centred at $V \simeq-425 \mathrm{~m} / \mathrm{s}$ ) and a relatively narrow range of spectral widths $(0-150 \mathrm{~m} / \mathrm{s})$. These echo populations are reminiscent of the statistical echo types identified earlier in the morning sector in Fig. 5. Further, the altitude histograms for the low-phase-velocity $(|V|<350 \mathrm{~m} / \mathrm{s})$ and high-phase-velocity $(|V|>350 \mathrm{~m} / \mathrm{s})$ echoes show that these echo types were separated in the virtual height; the low-velocity echoes were centred at $\sim 100 \mathrm{~km}$ and the high-velocity echoes at $\sim 150 \mathrm{~km}$. This result differs from the study by Milan et al. (2001) in which it was shown that both the highand low-velocity echoes originated close to the E-region peak altitude. An important feature regarding the high-phase-velocity echo population is seen in Fig. $8 \mathrm{~b}$ as the separation of these echoes according to their higher $\left(V_{e 0} \sim\right.$ $800 \mathrm{~m} / \mathrm{s}$, red points) and lower $\left(V_{e 0} \sim 500 \mathrm{~m} / \mathrm{s}\right.$, green points $)$ plasma drift speeds.

Figure 9 shows the normalised Doppler velocity versus the calculated flow 
angle (a) for all of the RKN E-region data between 20:20-20:40 UT and (b) for the high-velocity measurements only, $|V|>350 \mathrm{~m} / \mathrm{s}$. The normalised velocity shown is the Doppler velocity of the detected echo divided by the plasma drift speed given by the nearest fit vector. Each data point is colourcoded in (a) the virtual height and (b) the plasma drift speed. Also shown by the dashed line is the representative cosine of the flow angle, i.e. the expected flow angle variation of the normalised F-region plasma drift velocity.

Figure 9a shows that most echoes have normalised velocities with smaller magnitudes than that shown by the cosine curve, i.e. the cosine component of the background plasma flow. There also appears to be a lack of points with normalised velocity magnitudes greater than 0.6 for small flow angles, i.e. between $\theta=-10^{\circ}-20^{\circ}$. More importantly, the two populations of high- and low-velocity echoes that were identified in Fig. 8 as being separated by their measured Doppler velocities and virtual heights are not clearly separated in Fig. 9a. Instead these populations, which can be partly identified in Fig. 9a by their virtual heights, significantly overlap and do not show any clear difference in their normalised velocity variations with the flow angle. A distinct feature seen in Fig. 9a is however, the increase in the normalised velocity magnitude with altitude, which is most obvious between $\theta=20^{\circ}$ $60^{\circ}$.

In Fig. 9b, where the plotted data was restricted to the echoes with Doppler speeds greater than $350 \mathrm{~m} / \mathrm{s}$ and where the colour coding is in the drift speed, the high-velocity echoes appear to separate into two groups according to the associated plasma drift speed; this feature was also evident in Fig. 8b. Interestingly, the points associated with stronger plasma drifts, 700 $800 \mathrm{~m} / \mathrm{s}$, exhibit normalised velocities that are close to 0.5 , whilst the points associated with weaker plasma drifts, i.e. $400-500 \mathrm{~m} / \mathrm{s}$, exhibit normalised velocities that are actually higher, which is not necessarily expected. The high-velocity echo population (or the higher-altitude, from Fig. 8) also appears to comprise echoes belonging to two groups associated with lower and higher plasma drift speeds; this feature is seen only in their normalised velocities. The possible reasons for the unexpected decrease in the normalised velocity with drift speed and the associated splitting of the high-velocity echoes are discussed below. 


\section{Discussion}

In this study, the data collected by the PolarDARN HF radars were employed to analyse the characteristics of the E-region decametre-scale irregularities in the polar region. In the first part, the statistical characteristics of the short-range echoes were analysed including the temporal/spatial variations in occurrence as well as the spectral populations. In the second part, a new HF radar configuration was employed to directly compare the measured phase velocities from the $\mathrm{E}$ and $\mathrm{F}$ regions along the same magnetic field lines. These two aspects are discussed in separate sections below.

\subsection{Origin and characteristics of short-range PolarDARN echoes}

The first and most important step in the analysis of the E-region backscatter observed by the PolarDARN radars was to ensure that the E-region echoes were the major contributor to the dataset. It has been well-established that the short-range backscatter observed by the SuperDARN radars in the auroral region are predominantly of the E-region origin and as such a simple range cut-off exclusion criterion is often employed to remove the F-region backscatter (e.g. Makarevitch et al., 2002, 2004). Carter and Makarevich (2010) went even further by concluding that diffuse bands of echoes from the E region dominate these observations. However, in the case of some SuperDARN radars, such as the Syowa East radar, the F-region backscatter can also be detected at ranges as short as $450 \mathrm{~km}$ (e.g. Makarevich, 2010), so that the development of separate criteria may be needed for the PolarDARN radars.

To assess the amount of F-region echo contamination in the short ranges of the PolarDARN radars three different sets of F-region data exclusions were employed and the results were presented in Figs. 1 and 2. The last of the data exclusions included an upper boundary on the virtual height of the echoes which was chosen to be $200 \mathrm{~km}$. This additional criterion resulted in the significant weakening (removal) of the rather prominent echo bands in the farther ranges in the morning (midnight) sectors. A distinct feature seen from this analysis was a clear minimum in the echo counts and a decrease towards the largest ranges considered of $720 \mathrm{~km}$, particularly in the morning sector, Fig. 2. Another feature was a close resemblance between trends at very short ranges of $\leq 405 \mathrm{~km}$ (that are very unlikely to be of the F-region origin) and at all short ranges with the virtual height exclusion, Fig. 1. 
Both features strongly suggest that most of the contribution to the shortrange echoes (after virtual height exclusion applied) was from the E-region irregularities.

Other features in this analysis however, are at the first glance not so supportive of the above conclusion, including a second echo band at ranges $\sim 450 \mathrm{~km}$ which was observed together with a narrower band at and close to the very first range gate of $180 \mathrm{~km}$. This second band was mostly observed by RKN in the morning sector. Importantly, this feature is a new result as it is not consistent with the previous HF radar observations in the auroral and sub-auroral E regions. Thus in the auroral region only one echo band was observed in each time sector on a statistical basis (e.g. see most recent study by Makarevich, 2010, and references therein). The fact that this second band appeared as an integral part of the wider echo band at 450-720 km in Figs. $2 \mathrm{a}$ and $\mathrm{c}$, before the removal of high-altitude echoes, is in fact suggestive of its F-region origin. However, an indication that this may not be true was contained in Figs. 3 and 5, where the change in the occurrence of the second band from month to month matched that of the high-velocity echo population. This is further supported by the spatial occurrence patterns of only the high-velocity echoes (analogous to Fig. 3 but including echoes with phase velocities between 200 and $500 \mathrm{~m} / \mathrm{s}$, not displayed here), which showed that the majority of echoes composing the high-velocity echo population were detected within the far-range band. If the high-velocity echoes are a major contributor to this second band, it is unlikely to be of the F-region origin, as their preferential velocities near the undisturbed $C_{s}$ and a narrow width range are strong evidence that they are generated by the FBI. From the above, one can be quite confident that the major contribution to the PolarDARN datasets at ranges $\leq 720 \mathrm{~km}$ with $h^{\prime} \leq 200 \mathrm{~km}$ was from the E-region backscatter. However, it must be stated that the exclusion of the F-region echoes is by no means perfect even when using the virtual height information, which itself must be used with care (Chisham et al., 2008).

In further support of this conclusion, the spectral characteristic distributions of all short-range echoes with $h^{\prime} \leq 200 \mathrm{~km}$ in Figs. 5 and 6 were very similar to those reported in the past E-region HF studies (e.g. Eglitis et al., 1995; Milan and Lester, 2001; Makarevich, 2008, 2010); i.e. a dominant low-velocity echo population and a much smaller high-velocity echo population. In these works, the generation of the high-velocity echoes has been attributed to the FBI and the low-velocity echoes have generally been compared to the VHF Type II echoes and as such have been attributed to 
the GDI. However some studies have indicated that other nonlinear mechanisms, such as three-wave mode coupling (Sahr and Farley, 1995), that can significantly reduce the threshold phase velocity could also generate these low-velocity waves. An indication of the exact generation mechanisms can be sought from a statistical analysis of the flow-angle dependence (alternatively the L-shell-angle dependence in the case of L-shell aligned flow) of the velocity (e.g. Milan and Lester, 2001; Makarevich, 2008, 2010; Carter and Makarevich, 2009). However due to the high-latitudes of the observations reported here, the statistical flow patterns are not as simple as they are for the auroral observations and are hence difficult to determine accurately on a statistical basis. In light of the comments made previously by Hanuise (1983), the dominance of low-velocity echoes reported here was not necessarily an expected result due to the lack of horizontal gradients in the polar region. Although it would make sense that horizontal gradients would be commonly set up at these latitudes by the day-night terminator, in addition to the latitudinal boundaries of diffuse precipitation regions, resulting in significant quantities of GDI waves. Therefore, either the GDI is much more active in the polar region than previously thought or nonlinear plasma instabilities routinely generate low-velocity echoes that exhibit similar spectral characteristics to those reported by the auroral HF radars.

Another feature that is not easily explained is the number of echoes detected by both PolarDARN radars in the midnight sector relative to the morning sector, Figs. 1e and f. An analysis of the modelled L-shell and geometric aspect angles for the PolarDARN near-range FoVs, similar to that performed for other SuperDARN radars by Makarevich (2008), revealed that the L-shell and aspect angles are rather large for both radars: $\alpha>10^{\circ}$ and $\phi=50^{\circ}-110^{\circ}$ (not shown here). This implies that for the locations of small aspect angle to lie within the PolarDARN short-range FoVs elevated background plasma densities would be required. From this, it would be expected that the PolarDARN E-region backscatter would be more abundant in the morning (or daytime) sector than in the midnight sector due to increased solar illumination. The plasma density due to particle precipitation is expected to be quite low throughout the geomagnetically quiet period under study, with most contribution coming from solar illumination. However, the echo occurrence trends in Fig. 1 are not consistent with this expectation and instead show the exact opposite. Unfortunately, there exists no previous works that have also reported the diurnal trends of the E-region HF echo occurrence at such high latitudes with which our results could be compared. 
A more general problem is that observations of the E-region echoes at very high geometric aspect angles in the closer range gates imply very large plasma densities, if one believes that the echoes are coming from locations with small real (i.e. with refraction considered) aspect angles. In order to test this interpretation, the ionograms collected by the Canadian Advanced Digital Ionosonde (CADI) located at Rankin Inlet (Grant et al., 1995) were employed. Unfortunately, the Rankin Inlet ionosonde had very little data that coincided with the radar dataset at hand and as such did not allow a statistical comparison to be performed. The available good-quality ionograms collected by CADI on 20 Jun 2007 were analysed and compared to the range-versus-beam occurrence plots for the RKN data in the morning sector. It was found that $f_{0} E$ was close to $4 \mathrm{MHz}$, corresponding to a peak E-region plasma density of $\sim 2 \times 10^{5} \mathrm{~cm}^{-3}$. The real aspect angle (i.e. with refraction effects) can be determined by assuming a typical plasma density profile that is given by the IRI-2001 model (Bilitza, 2001) and using the geometric optics approach of Uspensky et al. (1994). This real aspect angle modelling was employed here, using the density inferred from the ionograms as the input. It showed that the small $\alpha$ locations matched that of the second echo band at farther ranges but not the first band near $180 \mathrm{~km}$; this is in further support of the interpretation that the far-range echo band is of E-region origin.

As the echo band in the midnight sector is similar to the first band near $180 \mathrm{~km}$ in the morning sector, the ionograms collected during the midnight sector on the same day were also analysed and compared with the RKN measurements. It was found that layers of enhanced plasma density, which are interpreted as sporadic $\mathrm{E}\left(f_{0} E_{s} \simeq 10 \mathrm{MHz}\right.$ that corresponds to a peak density of the order of $10^{6} \mathrm{~cm}^{-3}$ ), were regularly present during the midnight hours, roughly coinciding with periods of relatively high short-range echo detection rates observed by RKN. The lack of an exact correspondence in time between these phenomena could be due to the different viewing areas of RKN and CADI, which were at least $180 \mathrm{~km}$ apart. Employing instruments that cover the same ionospheric volume could provide further direct experimental support to this idea. It should be emphasised that the CADI observations from only 1 day are very unlikely to be representative of the statistical sporadic-E occurrence trends. Having said this, some evidence of a statistical relationship between the occurrence of the sporadic E and the polar E-region echoes in the midnight sector can be found in the work by Smith (1957). The diurnal and seasonal $E_{s}$ occurrence trends shown by Smith (1957) indicate that the detection of $E_{s}$ at Narsarssuak, Greenland 
$\left(70^{\circ}\right.$ magnetic latitude) is very high in the midnight sector $(50-70 \%)$ for all times of the year compared to the morning sector $(30-50 \%)$; see their Fig. II-D-3. In order to better understand the HF propagation conditions in relation to the sporadic E in the midnight sector, a future study that utilises the E-region plasma density measurements over an extended period of time within the PolarDARN FoVs, in addition to advanced ray-tracing modelling is required.

Due to the low sporadic-E occurrence reported by Smith (1957) in the morning sector, in addition to the lack of sporadic E observed by CADI during this time, it seems that the shortest-range echo band in the PolarDARN datasets is unlikely to be related to sporadic E layers. An alternative explanation is that the echoes within the first range gate are attributed to back-lobe scatter from the auroral region, south of the radar location (e.g. Milan et al., 1997). The three-way validation of the RKN velocity measurements by Koustov et al. (2009) showed that the effect of the back-lobe scatter was statistically insignificant in that study. However, it must be noted that the short-range echoes detected by RKN were not considered in that work and hence the observed feature may potentially be caused by the back-lobe scatter. It is also possible that other instrumental or software artefacts may cause this feature; e.g. $\mathrm{T} / \mathrm{R}$ switch timing and/or the sample delay being less than the assumed $1200 \mu \mathrm{s}$. However, from our results it seems unlikely that an instrument/software artefact is to blame, as one would expect this band to be observed constantly and not intermittently, from scan to scan.

One may also expect that a significant quantity of echoes with large velocity and width errors would contribute to the dataset analysed here, as these echoes were not explicitly excluded by the data selection criteria outlined in Sect. 2.1. These criteria are very similar to those employed in numerous previous studies of the auroral E-region irregularities using HF radars (e.g. Milan and Lester, 1998, 2001; Makarevich, 2008, 2010; Carter and Makarevich, 2009, 2010). For this reason, the same criteria were employed here as well. Nevertheless, the polar E-region irregularities remain relatively unexplored, particularly at $\mathrm{HF}$ and hence additional validation of the adopted criteria is required for the PolarDARN data. To achieve this, the dataset was further cleaned by only including echoes with velocity and spectral width errors < $100 \mathrm{~m} / \mathrm{s}$ and with backscatter power $>6 \mathrm{~dB}$ and the plots in Figs. 2-4 were reproduced (not shown here). The total number of echoes was diminished by $<30 \%$, however the statistical occurrence patterns displayed in Figs. 2-4, in addition to the echo populations shown in Figs. 5 and 6, were mostly 
unaffected. In particular, the total number of echoes (maximum within the plot) in the modified version of Fig. 3a was 244883 (2010) points compared to the original number 369580 (2918) shown in Fig. 3a. In addition, both of the short-range echo band (i.e. at the first range gate) and the second echo band at farther ranges remained after the exclusion of the large-error measurements. The location of the radar cell with the maximum number of echoes shifted between the respective plots, however this maximum was still found in the first range gate for all months except for 200810 for both radars in the plots analogous to Figs. $3 \mathrm{~d}$ and h. Similar to the spatial occurrence patterns for the morning sector, the major features shown in the plots for the midnight sector with the reduced dataset were almost identical. In particular, the total number of points (maximum within the plot) reduced from 343082 (3941) in Fig. 4a to 245043 (3228) in the reduced dataset, with the spatial patterns largely unchanged. Finally, the echo populations and their characteristics in Figs. 5 and 6 were almost identical with noticeable changes only in the total numbers. It is thus clear that the effects associated with inclusion of large-error measurements into the PolarDARN dataset did not affect the features and patterns observed in any significant way. It is also clear that the original data selection criteria adopted here work reasonably well in selecting the echoes that are well representative of good-quality echoes.

One other possibility is that the large number of echoes detected by both radars in the first range gate are the Polar Mesospheric Summer Echoes (PMSEs) that have been observed using other SuperDARN radars (e.g. Ogawa et al., 2002, 2003, 2004; Hosokawa et al., 2004, 2005). The PMSEs studied by these authors were also detected close to $180 \mathrm{~km}$ in range and are hence very similar in appearance to the echo bands shown in Fig. 3. Hosokawa et al. (2005) used the following set of criteria to extract the PMSE events from the dataset in order to study the statistical characteristics of these echoes: (1) backscatter power $>6 \mathrm{~dB}$, (2) Doppler velocity $<50 \mathrm{~m} / \mathrm{s}$ and (3) spectral width $<50 \mathrm{~m} / \mathrm{s}$. The plots analogous to Fig. 3 but for average power, velocity and width (not presented here) showed that echoes at 180 $\mathrm{km}$ had average quantities that were similar, although the scatter shown by the velocity-width distributions in Fig. 5 is too large to be entirely consistent with PMSE properties, e.g. both width and velocity regularly exceeded 50 $\mathrm{m} / \mathrm{s}$. Hosokawa et al. (2005) found that the occurrence of the PMSEs peaked some days after the summer solstice and were most frequently observed close to midday during the summer months. It appears that the PMSE occur- 
rence statistics reported by Hosokawa et al. (2005) are at odds with that displayed by the echoes in the first range gate of the PolarDARN radars. In particular, the monthly plots shown in Figs. 2 and 3 did not show a clear decrease in the number of echoes in the first range gate in the summer-autumn transition, which is what is expected if they were PMSEs. In addition, our occurrence peak in the morning sector, which mostly comprises the echoes in the first range gate, shows a peak close to 07 MLT and not midday, Figs. $1 \mathrm{e}$ and $\mathrm{f}$. Thus our initial assessment that most echoes at the short ranges of PolarDARN are of E-region origin remains largely unaffected.

\subsection{Irregularity phase velocities in the $E$ and $F$ regions}

In the second part of this PolarDARN study, the E-region phase velocities at HF were analysed for the first time using the F-region plasma flow estimates that were also obtained by HF radars, with coverage of both ionospheric regions on the same magnetic field lines.

A well-recognised problem in the studies of the E-region phase velocity is that it may be quite difficult to separate the effects of the flow angle from those due to the aspect angle attenuation (e.g. Foster et al., 1992; Makarevich and Carter, 2009). At HF, the problem is exacerbated since the aspect angle of a particular return echo cannot be known very accurately, and can only be estimated given an altitude profile of the electron density and then by calculating the real aspect angles (e.g. Uspensky et al., 2001; Koustov et al., 2001; Makarevitch et al., 2002). Figure 9 shows a large number of data points with velocities below the cosine of the plasma flow. One interpretation could be that these velocities are attenuated by larger aspect angles. However, it is not entirely clear that the aspect angle attenuation of the phase velocity is the cause of the large number of points with low normalised velocities. In this study we have employed a new way of circumventing this problem by using the measured backscatter power, as it is well-known that this quantity is also attenuated as the aspect angle deviates away from $0^{\circ}$ (e.g. Haldoupis, 1989). Therefore, the aspect angle attenuation effects are examined using the relative changes in the backscatter power as described below.

Figure 10 shows the normalised velocity versus the flow angle for the data points collected by RKN between 20:42-20:44 UT, 6 Aug 2007, colour-coded in the range-corrected power. In correcting for the power decrease with range $r$, it was assumed that the radar observes a scattering volume partiallyfilled with targets for which a SNR $\propto r^{-3}$ rule is appropriate (Greenwald et al., 1975). Also shown is the expected cosine variation of the plasma flow 


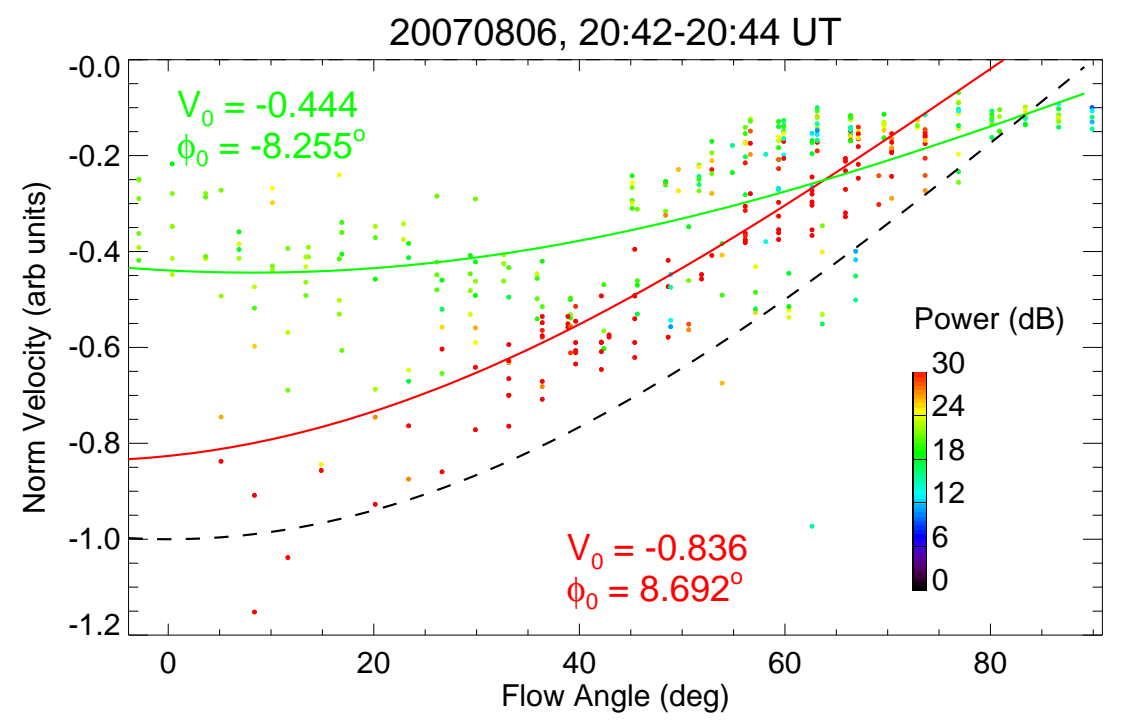

Figure 10: Same as Fig. 9a, but for the data collected at 20:42-20:44 UT on 6 Aug 2007 by the RKN radar. Also shown are the fitted cosine curves for the data with powers between 15-25 dB (green) and 25-35 dB (red), with the fitted parameters also displayed.

(dashed), in addition to the cosine fits to the higher-power (25-35 dB) and lower-power (15-25 dB) points shown in red and green, respectively. From Fig. 10, it is clear that the magnitude of the normalised phase velocity increases with increasing power (implying decreasing aspect angle), in accordance with the theoretical expectations. In particular, the phase velocity of the higher-power (i.e. red) points exhibits a cosine variation with the flow angle with an amplitude slightly lower than that of the plasma drift velocity component, i.e. the dashed line in Fig. 10. The lower-power (i.e. green) points also show a velocity variation that roughly follows the cosine of the flow angle, but with an even smaller amplitude, again indicating the aspect angle attenuation.

These results can be used further to give an estimate of the aspect sensitivity, which then can be compared with previous E-region irregularity observations. The fitted values for $V_{0}$ for the higher-power $(25-35 \mathrm{~dB})$ and lower-power $(15-25 \mathrm{~dB})$ points were $V_{0}=0.836$ and $V_{0}=0.444$, respectively. Inserting these values into the model based on the linear fluid theory predictions outlined by Makarevich and Carter (2009) (see their Fig. 4) for zero flow angle gives the aspect angles of $0.61^{\circ}$ and $1.63^{\circ}$, respectively. Hence, with a difference in power of $\sim 10 \mathrm{~dB}$, the estimate for the aspect sensitivity 
of these echoes is $9.8 \mathrm{~dB} / \mathrm{deg}$. This aspect sensitivity is very similar to the 10 $\mathrm{dB} / \mathrm{deg}$ reported using UHF radars at small aspect angles (e.g. Moorcroft, 1985; Foster et al., 1992), but is an order of magnitude larger than that reported using HF radars (e.g. Milan et al., 2004), for which it was suggested that observations of aspect angles as large as $30^{\circ}$ took place. As mentioned by Moorcroft (1996), the evidence in the literature suggests that the aspect sensitivity decreases with aspect angle, as aspect sensitivities close to that reported here have been observed for aspect angles less than $2^{\circ}$ (e.g. Foster et al., 1992; Moorcroft, 1985), whilst the estimates for larger aspect angles were smaller (e.g. Moorcroft, 1996). Therefore, from the estimates of the aspect angles using the linear theory predictions, the RKN E-region echo observations are in line with those reported previously.

A new result of the present study was a clear demonstration of the increased depression of the normalised phase velocity with decreasing altitude, Fig. 9a. This effect was most clear between the flow angles $20^{\circ}-60^{\circ}$, where the normalised phase velocity increased as the virtual height increased from $\sim 90 \mathrm{~km}$ towards $110 \mathrm{~km}$. This effect is likely to be due to collisions with the neutrals as described by the linear fluid theory. The effect of the ion and electron collisions with neutral particles is taken into account in the linear theory through the $\psi$ factor given by

$$
\psi=\frac{\nu_{e} \nu_{i}}{\Omega_{e} \Omega_{i}}
$$

where $\nu$ and $\Omega$ are the collision frequencies and the gyrofrequencies for the electrons $e$ and ions $i$, respectively, assuming zero aspect angle. The $\psi$ factor is related to the measured phase velocity $v_{p h}$ in the case of nonzero ion motions (i.e. $u_{i} \neq 0$ ) (e.g. Makarevich et al., 2007) by;

$$
v_{p h}=\frac{v_{d} \cos \theta}{1+\psi}+u_{i} \sin \theta
$$

where $v_{d}$ is the differential drift speed between the electrons and the ions. It is clear that $\psi$ is directly proportional to the collision frequencies which increase with decreasing altitude. From Eq. 4, it is also clear that as $\psi$ increases, the less dominant the $v_{d}$ term becomes. This leads to an increase in the dominance of the $u_{i}$ term. This last effect can also be seen in Fig. 9a in which the normalised velocity variation of the points with virtual heights between 90-110 km (i.e. light blue to green points) takes on a sine-like variation with the flow angle. In the previous studies, the collisional depression through 
$\nu_{e}$ and $\psi$ has often been invoked to explain small values of the E-region HF velocities observed (e.g. Makarevitch et al., 2004; Koustov et al., 2005), but with no supporting data being available. Here we clearly demonstrate that collisional depression becomes stronger with decreasing altitudes, i.e. it progressively becomes smaller than the plasma drift cosine component. This result represents a good example of the benefits of utilising the elevation angle measurements in combination with those of the plasma drift velocity.

An unexpected new result of the present study was the separation of a high-velocity echo population into two groups that were associated with different background plasma drift speeds, Figs. 8b and d, and that had very different normalised velocities as a result, Fig. 9b. Curiously enough, the high-velocity echoes that were associated with the stronger plasma drifts actually exhibited lower normalised velocities. One possible explanation for the different normalised velocities shown by these high-velocity populations is a difference in the aspect angles between these two groups of observations, i.e. assuming that the echoes with stronger drifts just happened to be observed at larger aspect angles. However, in using the new approach involving the backscatter power employed above, the data points in Fig. 9b coloured in power did not clearly separate into groups (not shown here), thus rendering this explanation unlikely.

The most probable explanation for the characteristics of the two highvelocity echo groups appears to be nonlocal effects in the FBI (Drexler et al., 2002) as explained below. In this framework, the phase velocity of the irregularities is strongly related to their growth rate. If the growth rate is large, the parallel group velocity increases dramatically and the phase velocity of the FBI waves becomes saturated at $C_{s}$. For the lower growth rates, the convective properties of the instability dominate and the phase velocity is no longer bound by $C_{s}$ but instead is close to the plasma drift velocity. The FBI waves observed at metre scales (i.e. VHF observations) are known to be associated with the growth rates of the order of $1000 \mathrm{~s}^{-1}$, whereas at decametre scales (i.e. for HF observations) the growth rates are of the order of only $1 \mathrm{~s}^{-1}$. Drexler et al. (2002) explain that these differences largely account for the apparent inconsistencies in the measured phase velocities between VHF and HF radar systems, i.e. metre-scale waves saturate at $C_{s}$, whilst the decametre waves are observed to have Doppler velocities in a much wider range (e.g. Eglitis et al., 1995; Milan and Lester, 2001; Makarevitch et al., 2002; Makarevich, 2008, 2010). It was put forward by Drexler et al. (2002) that the HF observations of the FBI waves that appear to be saturated at 
$C_{s}$ may be due to large growth rates associated with stronger electric fields in the order of $\sim 50 \mathrm{mV} / \mathrm{m}$ and above. In the present study, the observed difference in the background plasma flow speeds between the high-velocity echo groups is consistent with this idea. Our observations are also roughly consistent with the electric field threshold of $50 \mathrm{mV} / \mathrm{m}$ proposed by Drexler et al. (2002) as the limit between convective and non-convection regimes for the FBI waves. More specifically, the echoes that are (are not) saturated at 0.5 units of normalised velocity have a background plasma flow speed of $\sim$ $800(400) \mathrm{m} / \mathrm{s}$, corresponding to a driving electric field of $40(20) \mathrm{mV} / \mathrm{m}$. Thus it is proposed here that this result can be explained using a nonlocal formulation for the FBI.

\section{Summary and conclusions}

In this study, the characteristics of the E-region echoes received by the PolarDARN RKN and INV radars from magnetic latitudes $75^{\circ}-80^{\circ} \mathrm{N}$ were analysed both statistically and on a case-by-case basis.

The E-region echo occurrence patterns were found to be very different from those of the auroral SuperDARN radars in previous studies. Most of the E-region echoes were detected in the midnight sector at the very short ranges, where the geometric aspect angles are quite large for both PolarDARN radars. It is proposed that intense layers of ionisation strongly refract the $\mathrm{HF}$ radio waves regularly in the midnight sector, allowing detection of many coherent echoes close to the radar location. Low-velocity plasma waves, driven by the GDI or possibly other nonlinear mechanisms, dominated both radars' datasets, similar to the auroral SuperDARN radars, despite previous expectations that the horizontal gradients would be scarce in the polar region. In addition, a statistically significant quantity of high-velocity FBIdriven waves was observed in the morning sector, in accordance with the linear theoretical expectations of the small aspect and flow angles observed by PolarDARN during this period.

By employing the SuperDARN plasma flow vectors on the same magnetic field lines as the PolarDARN E-region measurements, it was clearly demonstrated that the depression of the irregularity velocity below the plasma drift component becomes stronger with decreasing altitude. This increasing depression is likely to be due to the more frequent collisions, which is combined with the aspect angle attenuation in depressing the Doppler velocity below its drift component. Further, the information provided by the plasma flow 
vectors enabled an estimation for the aspect sensitivity of $9.8 \mathrm{~dB} / \mathrm{deg}$, which is in good agreement with previous works that investigated aspect angles less than $2^{\circ}$. It was also found that the plasma waves generated by higher electric fields exhibited lower phase velocities than those generated by the lower electric fields, when normalised to the plasma drift speed. These characteristics are interpreted as being due to the convective nature of the two-stream plasma instability, with nonlocal effects also reducing the phase velocity.

Acknowledgements: The RKN and INV SuperDARN radars operations are funded by a MRS grant from Natural Sciences and Engineering Research Council of Canada (NSERC) and a Canadian Space Agency (CSA) contract. The CADI data and the ionogram analysis software was retrieved from the CHAIN website. The authors would like to thank A. C. Kellerman for his help with the SuperDARN plasma flow vector calculations. Fruitful discussions with A. V. Koustov and J. P. St.-Maurice are also kindly acknowledged.

\section{References}

Bilitza, D., 2001. International Reference Ionosphere 2000. Radio Sci. 36, $261-275$.

Carter, B.A., Makarevich, R.A., 2009. E-region decameter-scale plasma waves observed by the dual TIGER HF radars. Ann. Geophys. 27, 261-278.

Carter, B.A., Makarevich, R.A., 2010. On the diurnal variation of the Eregion coherent HF echo occurrence. J. Atmos. Sol. Terr. Phys. 72, 570582.

Chisham, G., Lester, M., Milan, S.E., Freeman, M.P., Bristow, W.A., Grocott, A., McWilliams, K.A., Ruohoniemi, J.M., Yeoman, T., Dyson, P.L., Greenwald, R.A., Kikuchi, T., Pinnock, M., Rash, J.P.S., Sato, N., Sofko, G.J., Villain, J.P., Walker, A.D.M., 2007. A decade of the Super Dual Auroral Radar Network (SuperDARN): scientific achievements, new techniques and future directions. Surv. Geophys. 28, 33-109.

Chisham, G., Yeoman, T., Sofko, G.J., 2008. Mapping ionospheric backscatter measured by the SuperDARN HF radars - Part 1: A new empirical virtual height model. Ann. Geophys. 26, 823-841. 
Drexler, J., St.-Maurice, J.P., Chen, D., Moorcroft, D.R., 2002. New insights from a nonlocal generalization of the Farley-Buneman instability problem at high latitudes. Ann. Geophys. 20, 2003-2025.

Eglitis, P., Robinson, T.R., McCrea, I.W., Schlegel, K., Nygren, T., Rodger, A.S., 1995. Doppler spectrum statistics obtained from three differentfrequency radar auroral experiments. Ann. Geophys. 13, 56-65.

Fejer, B.G., Kelley, M.C., 1980. Ionospheric irregularities. Geophys. Rev. 18, $401-454$

Fejer, B.G., Providakes, J., Farley, D.T., 1984. Theory of plasma waves in the auroral E region. J. Geophys. Res. 89, 7487-7494.

Foster, J.C., Tetenbaum, D., del Pozo, C.F., St-Maurice, J.P., Moorcroft, D.R., 1992. Aspect angle variations in intensity, phase velocity and altitude for high-latitude $34 \mathrm{~cm} E$ region irregularities. J. Geophys. Res. 97, 86018617.

Grant, I.F., MacDougall, J.W., Ruohoniemi, J.M., Bristow, W.A., Sofko, G.J., Koehler, J.A., Danskin, D., Andre, D., 1995. Comparison of plasma flow velocities determined by the ionosonde Doppler drift technique, SuperDARN radars, and patch motion. Radio Sci. 30, 1537-1549.

Greenwald, R.A., Baker, K.B., Dudeney, J.R., Pinnock, M., Jones, T.B., Thomas, E.C., Villain, J.P., Cerisier, J.C., Senior, C., Hanuise, C., Hunsuker, R.D., Sofko, G., Koehler, J., Nielsen, E., Pellinen, R., Walker, A.D.M., Sato, N., Yamagishi, H., 1995. DARN/SuperDARN: A global view of the dynamics of high-latitude convection. Space Sci. Rev. 71, 763796.

Greenwald, R.A., Ecklund, W.L., Balsley, B.B., 1975. Radar observations of auroral electrojet currents. J. Geophys. Res. 80, 3635-3641.

Haldoupis, C., 1989. A review on radio studies of auroral E region ionospheric irregularities. Ann. Geophys. 7, 239-258.

Hanuise, C., 1983. High latitude ionospheric irregularities. Radio Sci. 18, 1093-1121. 
Hosokawa, K., Ogawa, T., Arnold, N.F., Lester, M., Sato, N., Yukimatu, A.S., 2005. Extraction of polar mesosphere summer echoes from SuperDARN data. Geophys. Res. Lett. 32, L12801, doi:10.1029/2005GL022788.

Hosokawa, K., Ogawa, T., Yukimatu, A.S., Sato, N., Iyemori, T., 2004. Statistics of Antarctic mesospheric echoes observed with the SuperDARN Syowa radar. Geophys. Res. Lett. 31, L02106, doi:10.1029/2003GL018776.

Iverson, I.B., D'Angelo, N., Olesen, J.K., 1975. Further evidence for the Farley-Buneman instability in the polar cap ionosphere. J. Geophys. Res. 80, 3713-3714.

Koustov, A.V., Danskin, D.W., Makarevitch, R.A., Gorin, J.D., 2005. On the relationship between the velocity of E-region HF echoes and ExB plasma drift. Ann. Geophys. 23, 371-378.

Koustov, A.V., Danskin, D.W., Uspensky, M.V., Ogawa, T., Janhunen, P., Nishitani, N., Nozawa, S., Lester, M., Milan, S., 2002. Velocities of auroral coherent echoes at 12 and $144 \mathrm{MHz}$. Ann. Geophys. 20, 1647-1662.

Koustov, A.V., Igarashi, K., André, D., Ohtaka, K., Sato, N., Yamagishi, H., Yukimatu, A., 2001. Observations of 50- and 12-MHz auroral coherent echoes at the Antarctic Syowa station. J. Geophys. Res. 106, 12875-12887.

Koustov, A.V., St.-Maurice, J.P., Sofko, G.J., Andre, D., MacDougall, J.W., Hairston, M.R., Fiori, R.A., Kadochnikov, E.E., 2009. Three-way validation of the Rankin Inlet PolarDARN radar velocity measurements. Radio Sci. 44, RS4003, doi:10.1029/2008RS004045.

Kustov, A.V., Gromova, L.I., Feldstien, Y.I., Levitin, A.E., Danskin, D., Koehler, J.A., Sofko, G.J., McKibben, M., 1994. Electrodynamics of the upper atmosphere and radio aurora in the northern polar cap. Geom. Aeron. 34, 157-165.

Kustov, A.V., Koehler, J.A., Sofko, G.J., Danskin, D.W., 1996. The SAPPHIRE-North radar experiment: Observations of discrete and diffuse echoes. J. Geophys. Res. 101, 7973-7986.

Kustov, A.V., Koehler, J.A., Sofko, G.J., Danskin, D.W., Schiffler, A., 1997. Relationship of the SAPPHIRE-North merged velocity and the plasma 
convection velocity derived from simultaneous SuperDARN radar measurements. J. Geophys. Res. 102, 2495-2501.

Makarevich, R.A., 2008. HF radar observations of high-velocity E-region echoes from the eastward auroral electrojet. J. Geophys. Res. 113, A09321, doi:10.1029/2008JA013204.

Makarevich, R.A., 2010. On the occurrence of high-velocity E-region echoes in SuperDARN observations. J. Geophys. Res. 115, A07302, doi:10.1029/2009JA014698.

Makarevich, R.A., Carter, B.A., 2009. HF echo types revisted: aspect angle attenuation effects. Ann. Geophys. 27, 3065-3075.

Makarevich, R.A., Honary, F., Howells, V.S.C., Koustov, A.V., Milan, S.E., Davies, J.A., Senior, A., McCrea, I.W., Dyson, P.L., 2006a. A first comparison of irregularity and ion drift velocity measurements in the E region. Ann. Geophys. 24, 2375-2389.

Makarevich, R.A., Koustov, A.V., Senior, A., Uspensky, M., Honary, F., Dyson, P.L., 2007. Aspect angle dependence of the E-region irregularity velocity at large flow angles. J. Geophys. Res. 112, A11303, doi:10.1029/2007JA012342.

Makarevich, R.A., Senior, A., Koustov, A.V., Uspensky, M.V., Honary, F., Dyson, P.L., 2006b. A study of aspect angle effects in the E-region irregularity velocity using multi-point electric field measurements. Geophys. Res. Lett. 33, L21102, doi:10.1029/2006GL027740.

Makarevitch, R.A., Honary, F., Koustov, A.V., 2004. Simultaneous HF measurements of E- and F-region Doppler velocity at large flow angles. Ann. Geophys. 22, 1177-1188.

Makarevitch, R.A., Koustov, A.V., Igarashi, K., Sato, N., Ogawa, T., Ohtaka, K., Yamagishi, H., Yukimatu, A.S., 2002. Comparison of flow angle variations of E-region echo characteristics at VHF and HF. Adv. Polar Upper Atmos. Res. 16, 59-83.

Maus, S., Macmillan, S., Chernova, T., Choi, S., Dater, D., Golovkov, V., Lesur, V., Lowes, F., Luhr, H., Mai, W., McLean, S., Olsen, N., Rother, M., Sabaka, T., Thomson, A., Zvereva, T., 2005. The 10th generation 
international geomagnetic reference field. Phys. Earth Planet. Inter. 151, $320-322$.

Milan, S.E., Jones, T.B., Robinson, T.R., Thomas, E.C., Yeoman, T.K., 1997. Interferometric evidence for the observation of ground scatter originating behind the CUTLASS coherent HF radars. Ann. Geophys. 15, 29-39.

Milan, S.E., Lester, M., 1998. Simultaneous observations at different altitudes of ionospheric backscatter in the eastward electrojet. Ann. Geophys. 16, $55-68$.

Milan, S.E., Lester, M., 2001. A classification of spectral populations observed in $\mathrm{HF}$ radar backscatter from the E region auroral electrojets. Ann. Geophys. 19, 189-204.

Milan, S.E., Lester, M., Sato, N., 2003. Multi-frequency observations of E region HF radar aurora. Ann. Geophys. 21, 761-777.

Milan, S.E., Lester, M., Sato, N., Takizawa, H., 2001. On the altitude dependence of the spectral characteristics of decametre-wavelength E region backscatter and the relationship with optical auroral forms. Ann. Geophys. 19, 205-217.

Milan, S.E., Lester, M., Yeoman, T.K., Robinson, T.R., Uspensky, M.V., Villain, J.P., 2004. HF radar observations of high-aspect angle backscatter from the E region. Ann. Geophys. 22, 829-847.

Moorcroft, D.R., 1985. An examination of radio-auroral aspect sensitivity. Can. J. Phys. 63, 1005-1012.

Moorcroft, D.R., 1996. A statistical study of UHF auroral backscatter at large magnetic aspect angle: A reanalysis of unpublished results from 1968. J. Geophys. Res. 101, 11005-11011.

Nielsen, E., Schlegel, K., 1983. A first comparison of STARE and EISCAT electron drift velocity measurements. J. Geophys. Res. 88, 5745-5750.

Nielsen, E., Schlegel, K., 1985. Coherent radar Doppler measurements and their relationship to the ionospheric electron drift velocity. J. Geophys. Res. 90, 3498-3504. 
Ogawa, T., Arnold, N.F., Kirkwood, S., Nishitani, N., Lester, M., 2003. Finland HF and Esrange MST radar observations of polar mesosphere summer echoes. Ann. Geophys. 21, 1047-1055.

Ogawa, T., Nishitani, N., Sato, N., Yamagishi, H., Yukimatu, A.S., 2002. Upper mesosphere summer echoes detected with the Antarctic Syowa HF radar. Geophys. Res. Lett. 29, 1157, doi:10.1029/2001GL014094.

Ogawa, T., Nozawa, S., Tsutsumi, M., Arnold, N.F., Nishitani, N., Sato3, N., Yukimatu, A.S., 2004. Arctic and Antarctic polar mesosphere summer echoes observed with oblique incidence HF radars: analysis using simultaneous MF and VHF radar data. Ann. Geophys. 22, 4049-4059.

Olesen, J.K., Primdahl, R., Spangslev, F., D’Angelo, N., 1975. On the Farley instability in the polar cap E region. J. Geophys. Res. 80, 696-698.

Pettigrew, E.D., Shepherd, S.G., Ruohoniemi, J.M., 2010. Climatological patterns of high-latitude convection in the Northern and Southern hemispheres: Dipole tilt dependencies and interhemispheric comparisons. J. Geophys. Res. 115, A07305, doi:10.1029/2009JA014956.

Ruohoniemi, J.M., Baker, K.B., 1998. Large-scale imaging of high-latitude convection with Super Dual Auroral Radar Network HF radar observations. J. Geophys. Res. 103, 20797-20811.

Ruohoniemi, J.M., Greenwald, R.A., 2005. Dependencies of high-latitude plasma convection: Consideration of interplanetary magnetic field, seasonal, and universal time factors in statistical patterns. J. Geophys. Res. 110, A09204, doi:10.1029/2004JA010815.

Sahr, J., Fejer, B.G., 1996. Auroral electrojet plasma irregularity theory and experiment: A critical review of present understanding and future directions. J. Geophys. Res. 101, 26893-26909.

Sahr, J.D., Farley, D.T., 1995. Three wave coupling in the auroral $E$ region. Ann. Geophys. 13, 38-44.

Simon, A., 1963. Instability of a partially ionized plasma in a crossed electric and magnetic fields. Phys. Fluids 6, 382-388. 
Smith, E.K., 1957. World-wide occurrence of sporadic E. Circular 582, National Bureau of Standards, USA.

Tsunoda, R.T., Perreault, P.D., Hodges, J.C., 1976. Azimuthal distribution of HF slant E echoes and its relationship to the polar cap electric field. J. Geophys. Res. 81, 3834-3844.

Uspensky, M., Koustov, A., Janhunen, P., Nielsen, E., Kauristie, K., Amm, O., Pellinen, R., Opgenoorth, H., Pirjola, R., 2004. STARE velocities: 2 Evening westward electron flow. Ann. Geophys. 22, 1077-1091.

Uspensky, M., Koustov, A., Janhunen, P., Pellinen, R., Danskin, D., Nozawa, S., 2003. STARE velocities: the importance of off-orthogonality and ion motions. Ann. Geophys. 21, 729-743.

Uspensky, M.V., Koustov, A.V., Eglitis, P., Huuskonen, A., Milan, S.E., Pulkkinen, T., Pirjola, R., 2001. CUTLASS HF radar observations of high-velocity E-region echoes. Ann. Geophys. 19, 411-424.

Uspensky, M.V., Kustov, A.V., Sofko, G.J., Koehler, J.A., Villain, J.P., Hanuise, C., Ruohoniemi, J.M., Williams, P.J.S., 1994. Ionospheric refraction effects in slant range profiles of auroral HF coherent echoes. Radio Sci. 29, 503-517.

Villain, J.P., Greenwald, R.A., Baker, K.B., Ruohoniemi, J.M., 1987. HF radar observations of $\mathrm{E}$ region plasma irregularities produced by oblique electron streaming. J. Geophys. Res. 92, 12327-12342.

Villain, J.P., Hanuise, C., Greenwald, R.A., Baker, K.B., Ruohoniemi, J.M., 1990. Obliquely propagating ion acoustic waves in the auroral E region: Further evidence of irregularity production by field-aligned electron streaming. J. Geophys. Res. 95, 7833-7846. 